\title{
Influence of Interfacial Reactions on the Fiber-Matrix Interfacial Shear-Strength in Sapphire Fiber-Reinforced Nial(Yb) Composites
}

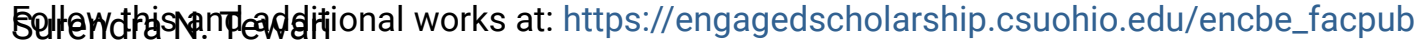

Keland State University

R.oAsetperfaaccess to this work benefit you? Let us know!

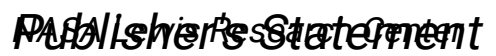

Kopyright 1995 ASM International. This paper was published in Metallurgical and Materials

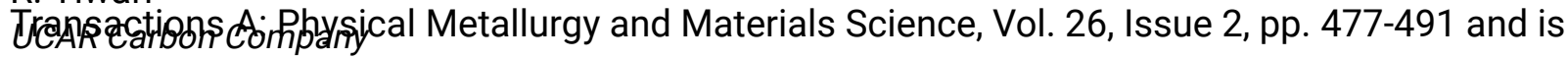
made available as an electronic reprint with the permission of ASM International. One print or etedtronwman ${ }^{R}$ may be made for personal use only. Systematic or multiple reproduction, NASA Lewis Research Center distribution to multiple locations via electronic or other means, duplications of any material in thi@miatber for a fee or for commercial purposes, or modification of the content of this paper are Glokibited. State University

Available on publisher's site at: http://hts.asminternational.org/portal/site/www/AsmStore/ ProductDetails/?vgnextoid=22859f28a0fc7210VgnVCM100000621e010aRCRD.

\section{Original Citation}

Tewari, S.N., Asthana, R., Tiwari, R., Bowman, R.R., \& Smith, J. (1995). Influence of Interfacial Reactions on the Fiber-Matrix Interfacial Shear-Strength in Sapphire Fiber-Reinforced Nial(Yb) Composites.

Metallurgical and Materials Transactions A: Physical Metallurgy and Materials Science 26, 477-491.

\section{Repository Citation}

Tewari, Surendra N.; Asthana, R.; Tiwari, R.; Bowman, R. R.; and Smith, J., "Influence of Interfacial Reactions on the Fiber-Matrix Interfacial Shear-Strength in Sapphire Fiber-Reinforced Nial(Yb) Composites" (1995). Chemical \& Biomedical Engineering Faculty Publications. 24.

https://engagedscholarship.csuohio.edu/encbe_facpub/24

This Article is brought to you for free and open access by the Chemical \& Biomedical Engineering Department at EngagedScholarship@CSU. It has been accepted for inclusion in Chemical \& Biomedical Engineering Faculty Publications by an authorized administrator of EngagedScholarship@CSU. For more information, please contact library.es@csuohio.edu. 


\title{
Influence of Interfacial Reactions on the Fiber-Matrix Interfacial Shear Strength in Sapphire Fiber-Reinforced $\mathrm{NiAl}(\mathrm{Yb})$ Composites
}

\author{
S.N. TEWARI, R. ASTHANA, R. TIWARI, R.R. BOWMAN, and J. SMITH
}

\begin{abstract}
The influence of microstructure of the fiber-matrix interface on the interfacial shear strength, measured using a fiber-pushout technique, has been examined in a sapphire-fiber-reinforced $\mathrm{NiAl}(\mathrm{Yb})$ matrix composite under the following conditions: (1) as-fabricated powder metallurgy (PM) composites, (2) PM composites after solid-state heat treatment (HT), and (3) PM composites after directional solidification (DS). The fiber-pushout stress-displacement behavior consisted of an initial "pseudoelastic" region, wherein the stress increased linearly with displacement, followed by an "inelastic" region, where the slope of the stress-displacement plot decreased until a maximum stress was reached, and the subsequent gradual stress decreased to a "frictional" stress. Energy-dispersive spectroscopy (EDS) and X-ray analyses showed that the interfacial region in the $\mathrm{PM} \mathrm{NiAl}(\mathrm{Yb})$ composites was comprised of $\mathrm{Yb}_{2} \mathrm{O}_{3}$, O-rich $\mathrm{NiAl}$ and some spinel oxide $\left(\mathrm{Yb}_{3} \mathrm{Al}_{5} \mathrm{O}_{12}\right)$, whereas the interfacial region in the HT and DS composites was comprised mainly of $\mathrm{Yb}_{3} \mathrm{Al}_{5} \mathrm{O}_{12}$. A reaction mechanism has been proposed to explain the presence of interfacial species observed in the sapphire- $\mathrm{NiAl}(\mathrm{Yb})$ composite. The extent of interfacial chemical reactions and severity of fiber surface degradation increased progressively in this order: $\mathrm{PM}<\mathrm{HT}<\mathrm{DS}$. Chemical interactions between the fiber and the $\mathrm{NiAl}(\mathrm{Yb})$ matrix resulted in chemical bonding and higher interfacial shear strength compared to sapphire-NiAl composites without $\mathrm{Yb}$. Unlike the sapphire-NiAl system, the frictional shear stress in the sapphire-NiAl $(\mathrm{Yb})$ composites was strongly dependent on the processing conditions.
\end{abstract}

\section{INTRODUCTION}

THE nickel base intermetallic, $\operatorname{NiAl}(\beta)$, is being extensively investigated for high-temperature structural applications because of its high melting point, low density, high modulus, good thermal conductivity, and outstanding oxidation resistance. ${ }^{[1,2]}$ However, NiAl suffers from low elevated-temperature strength and very poor low- to intermediate-temperature toughness and plastic ductility. It is believed that these limitations can be overcome by refractory fiber reinforcement. Sapphire-fiber-reinforced $\mathrm{NiAl}$ composites, made by powder metallurgy techniques, are therefore being seriously investigated. ${ }^{|3.4 .5|}$ The extent of strengthening and toughening imparted by the fibers is expected to depend on the microstructure of the fiber-matrix interface. Load-displacement measurements during fiber-pushout testing ${ }^{|3,5|}$ provide a measure of the interfacial shear strengths. However, a systematic study into the influence of the fiber-matrix interface on the deformation behavior during fiber pushout in sapphirefiber-reinforced NiAl composites is lacking. Hence, the goal of the present study was to address these issues. In this study, two methods have been used to vary the microstructure at the fiber-matrix interface: (1) alloying

S.N. TEWARI, Professor, and J. SMITH, Research Associate, are with the Department of Chemical Engineering, Cleveland State University, Cleveland, OH 44115. R. ASTHANA, National Research Council Associate, is with the Materials Division, NASA Lewis Research Center, Cleveland, $\mathrm{OH}$ 44135. R. TIWARI, Formerly Research Associate, Department of Chemical Engineering, Cleveland State University, is Staff Scientist with UCAR Carbon Company, Cleveland, OH 44101. R.R. BOWMAN, Engineer, is with the Intermetallics Branch, NASA Lewis Research Center, Cleveland, $\mathrm{OH}$ 44135 .

Manuscript submitted December 20, 1993. of $\mathrm{NiAl}$ by ytterbium $(\mathrm{Yb})$ and (2) use of solid-state heat treatment $(\mathrm{HT})$ and directional solidification (DS) to modify the interfaces in the as-fabricated powder metallurgy (PM) sapphire-NiAl( $\mathrm{Yb})$ composites. The powder-cloth (PC) process, ${ }^{[3,4]}$ which is essentially a PM technique, was selected for the fabrication of the composites in order to obtain fine, equiaxed- $\mathrm{NiAl}$ grains in contact with the sapphire fibers. Heat treatment and zone DS of the PC-processed composite feed stock ${ }^{[6,7]}$ were selected to enhance the extent of fiber-matrix reaction and to obtain large $\mathrm{NiAl}$ grains in contact with the fiber. Because $\mathrm{NiAl}$ does not react with alumina, ${ }^{[8]}$ the $\mathrm{NiAl}$ melt was not expected to wet the sapphire fiber. Ytterbium was selected as an alloying addition to $\mathrm{NiAl}$, because ytterbium oxide is thermodynamically more stable than aluminum oxide ${ }^{\mid 9]}$ and therefore a chemical reaction between the sapphire fibers and $\mathrm{Yb}$ in the matrix would be expected. It has been reported ${ }^{[10]}$ that the adhesion of the $\mathrm{Al}_{2} \mathrm{O}_{3}$ oxide scale to the $\mathrm{Ni}-\mathrm{Al}$ alloys is enhanced by the addition of rare earth elements. Thus, the addition of $\mathrm{Yb}$ to the NiAl matrix could also lead to improved bonding between the sapphire fiber and the NiAl matrix. This study compares the fiber-matrix interfacial microstructure and the fiber-pushout response of PM, HT, and DS sapphire- $\mathrm{NiAl}(\mathrm{Yb})$ composites with interfacial microstructure and fiber-pushout behavior of PM and DS sapphire-NiAl composites.

\section{EXPERIMENTAL PROCEDURE}

The composite feedstock specimens (fiber volume fraction: 28 vol pct) were fabricated by the PC process $^{(3,4)}$ using powders of either near-stoichiometric, singlephase $\mathrm{NiAl}$, or an aluminum-rich $\mathrm{NiAl}(\mathrm{Yb})$, and 
combining these powders with single-crystal sapphire fibers (Saphikon, Milford, NH) of about $130-\mu \mathrm{m}$ diameter. In the PC process, cloths of matrix alloy, formed by mixing powders combined with organic binders, are placed between plies made up of rows of alumina fibers and are diffusion bonded by application of high pressures and high temperatures. The PM composite plates $(0.25 \mathrm{~cm}$ by $0.4-\mathrm{cm}$ cross section) were subsequently used as feed material for HT and zone DS using a $30-\mathrm{kW}$ RF generator. For the present set of experiments, solid-state HT and DS were carried out by creating a hot zone (molten, in the case of DS) of $0.6-$ to $0.8-\mathrm{cm}$ length in the feedstock bar, using a copper concentrator $(1.25-\mathrm{cm}-$ diameter hole) and traversing this zone at a speed of $6.0 \mathrm{~cm}$ per hour along the length of the feed specimen. A positive $20 \mathrm{kPa}$ pressure of ultra-high-purity argon was used to suppress the loss of aluminum because of its high vapor pressure. A radiation pyrometer was used to control the temperature of the zone to within $\pm 6 \mathrm{~K}$ of the desired temperature.

The fiber-matrix interfacial shear strengths of PM, HT, and DS composites were measured using a desktop fiberpushout-test apparatus. ${ }^{[11]}$ This device records the time dependence of load during pushing (compressing) of a single sapphire fiber embedded in the $\mathrm{NiAl}$ matrix by using a flat-bottomed punch of sintered tungsten carbide (102- $\mu \mathrm{m}$ diameter). The samples for pushout testing were in the form of flat discs (nominal thickness: 300 to $400 \mu \mathrm{m})$ with a metallographic surface finish. The disks were firmly glued to a steel sample holder having $400-\mu \mathrm{m}$ wide grooves, taking care to align the fibers over the grooves so as to enable their unobstructed sliding during the pushout test. A motorized traverse mechanism allowed the sample to be moved toward the stationary punch at a rate of $0.82 \mu \mathrm{m} \mathrm{s}^{-1}$. The load $v s$ time data were recorded at 50-ms intervals for a period of 180 seconds or less and stored in computer files. In addition, acoustic emission (AE) was also recorded during the fiber-pushout process. Generally, 10 to 30 tests were performed for each processing condition.

The grain structure in the matrix was revealed by etching metallographically polished samples with a solution of $25 \mathrm{vol}$ pet acetic acid, $25 \mathrm{vol}$ pet nitric acid, and $50 \mathrm{vol}$ pct distilled water. The debonded fiber and matrix surfaces from the pushout-test specimens were examined in a Cambridge 2000 scanning electron microscope (SEM). The sapphire fibers were extracted from the PM, HT, and DS composites for SEM examination by dissolving the matrix in a solution of $75 \mathrm{~mL}$ acetic acid (glacial), $25 \mathrm{~mL}$ concentrated $\mathrm{HNO}_{3}$ acid, and $2 \mathrm{~mL}$ concentrated $\mathrm{HCl}$. The fracture (debonding) behavior during fiber pushout was examined by interrupting the pushout test and examining the front faces (the sample surface in contact with the tungsten carbide punch) and back faces of the samples in the vicinity of the fibers by SEM. Energy dispersive X-ray spectroscopy (EDS) and $\mathrm{X}$-ray diffraction were used to identify the phases present.

\section{RESULTS}

\section{A. Chemical Analyses and X-ray Diffraction of Composite Matrices}

The chemical compositions of the PC processed PM, $\mathrm{HT}$, and DS NiAl(Yb) matrices (after dissolving the matrix and removing the fibers), as determined by inductively coupled emission spectroscopy, are listed in Table I. The nickel and aluminum contents of the matrices did not change because of HT and DS; however, there was nearly a 50 to 70 pct decrease in the $\mathrm{Yb}$ content of the matrix in the DS and HT composites.

The results of X-ray analysis summarized in Table I show that both the PM and DS NiAl composites contained near-stoichiometric $\mathrm{NiAl}$ (with a lattice parameter of $0.2878 \mathrm{~nm}$ for PM and $0.2886 \mathrm{~nm}$ for DS material) and $\alpha-\mathrm{Al}_{2} \mathrm{O}_{3}$. Also, the $\mathrm{PM} \mathrm{NiAl}(\mathrm{Yb})$ composites contained $\mathrm{NiAl}, \alpha-\mathrm{Al}_{2} \mathrm{O}_{3}, \mathrm{Yb}_{2} \mathrm{O}_{3}$, and $\mathrm{Yb}_{3} \mathrm{Al}_{5} \mathrm{O}_{12}$ phases. The lattice parameter of the $\mathrm{NiAl}(\mathrm{Yb})$ lattice, determined from the (100) and (110) reflections, was $0.2867 \mathrm{~nm}$. In the case of $\mathrm{HT} \mathrm{NiAl}(\mathrm{Yb})$ composites, the phases present were $\mathrm{NiAl}, \alpha-\mathrm{Al}_{2} \mathrm{O}_{3}, \mathrm{NiAl}$ martensite, and the spinel oxide $\mathrm{Yb}_{3} \mathrm{Al}_{5} \mathrm{O}_{12}$, and the DS NiAl( $\left.\mathrm{Yb}\right)$ composites contained $\mathrm{NiAl}, \boldsymbol{\alpha}-\mathrm{Al}_{2} \mathrm{O}_{3}, \quad \mathrm{Yb}_{3} \mathrm{Al}_{5} \mathrm{O}_{12}$, and $\mathrm{Ni}_{3} \mathrm{Al}$ phases. The $\operatorname{NiAl}(\mathrm{Yb})$ lattice parameters for the HT and DS $\operatorname{NiAl}(\mathrm{Yb})$ composites were 0.2861 and $0.2856 \mathrm{~nm}$, respectively.

\section{B. Microstructure}

Figures 1(a) through (e) show typical transverse microstructures (normal to the fibers) of the sapphire fiberreinforced composites. Each figure contains a lowmagnification overall view that shows the distribution of fibers and also a high-magnification view that shows the matrix microstructure in the vicinity of the sapphire fibers. The average grain sizes of the PM NiAl and PM $\mathrm{NiAl}(\mathrm{Yb})$ specimens (measured on the transverse sections) were 50 and $80 \mu \mathrm{m}$, respectively. In comparison, the grain sizes of the $\mathrm{DS} \mathrm{NiAl}$ and $\mathrm{NiAl}(\mathrm{Yb})$ specimens were 1000 and $230 \mu \mathrm{m}$, respectively. The $\mathrm{HT}-\mathrm{NiAl}(\mathrm{Yb})$ specimens had an intermediate grain size of about $135 \mu \mathrm{m}$. Because of the smaller matrix grain size in the PM material compared to the HT and the DS material, the number of grain boundaries coincident on the fiber surface in PM material was much greater than in the HT and the DS specimens. There was occasional microporosity located at some of the grain boundary junctions in the matrices of PM specimens, marked by arrows in Figures 1(a) and (b). The DS (Figure 1(d)) and the HT (Figure 1(e)) sapphire-NiAl(Yb) specimens show microporosity and some matrix cracking.

The light phase along the grain boundaries in the PM, $\mathrm{HT}$, and $\mathrm{DS} \mathrm{NiAl}(\mathrm{Yb})$ specimens (marked by an arrow in Figures 1(b), (d), and (e)) was identified by EDS as $\mathrm{Ni}_{3} \mathrm{Al}$ (the $\mathrm{Ni}_{3} \mathrm{Al}$ phase was not detected in the PM$\mathrm{NiAl}(\mathrm{Yb})$ by $\mathrm{X}$-ray analysis described previously). Although the lenticular markings in the DS and $\mathrm{HT} \mathrm{NiAl(Yb)}$ matrix (Figures $1(\mathrm{~d})$ and (e)) strongly suggest the presence of martensite (which is expected to form in $\mathrm{NiAl}$ alloys with less than 37 at. pct $\mathrm{Al}^{[12]}$ ), X-ray analysis could not confirm its presence. Optical microscopy also revealed a severe chemical reaction between the fiber and matrix in the PM (Figure 1(b)), DS (Figure 1(d)), and HT (Figure 1(e)) sapphire-NiAl(Yb) specimens. In contrast, no fiber-matrix reaction was observed in the PM (Figure 1(a)) and DS (Figure 1(c)) sapphire-NiAl composites. 
Table I. Summary of Chemical and X-Ray Phase Analysis of the PM and DS Sapphire-Reinforced NiAl(Yb) Composites*

\begin{tabular}{lcccl}
\hline \multicolumn{1}{c}{ Material } & $\begin{array}{c}\mathrm{Ni} \\
\text { (At. Pct) }\end{array}$ & $\begin{array}{c}\mathrm{Al} \\
\text { (At. Pct) }\end{array}$ & $\begin{array}{c}\mathrm{Yb} \\
\text { (At. Pct) }\end{array}$ \\
\hline PM-NiAl & 49.9 & 50.1 & - & \multicolumn{1}{c}{ Phases Present } \\
DS-NiAl & 50.3 & 49.7 & - & $\mathrm{NiAl}$ and $\mathrm{Al}_{2} \mathrm{O}_{3}$ \\
PM-NiAl(Yb) & 62.1 & 36.8 & 0.36 & $\mathrm{NiAl} \mathrm{and} \mathrm{Al}_{2} \mathrm{O}_{3}$ \\
HT-NiAl(Yb) & 62.6 & 37.3 & 0.11 & $\mathrm{NiAl}, \mathrm{Al}_{2} \mathrm{O}_{3}, \mathrm{Yb}_{2} \mathrm{O}_{3}, \mathrm{Yb}_{3} \mathrm{Al}_{3} \mathrm{O}_{12}$, and $\mathrm{Yb}_{3} \mathrm{Al}_{3} \mathrm{O}_{12}$ \\
DS-NiAl(Yb) & 62.5 & 36.4 & 0.19 & $\mathrm{NiAl}_{2} \mathrm{Al}_{2} \mathrm{O}_{3}, \mathrm{Yb}_{3} \mathrm{Al}_{5} \mathrm{O}_{12}$, and $\mathrm{Ni}_{3} \mathrm{Al}$ \\
\hline
\end{tabular}

*The chemical compositions were determined to 5 pet relative accuracy.

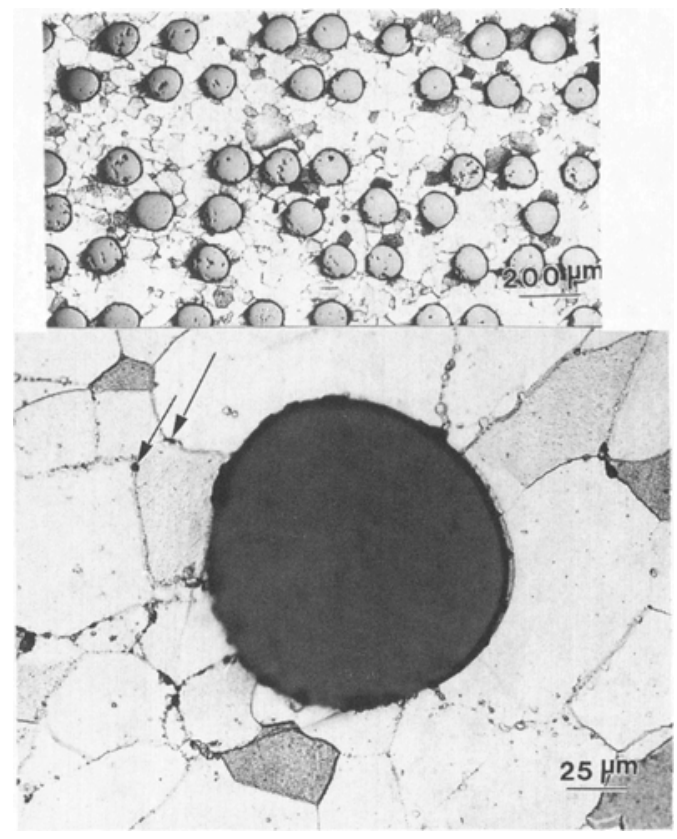

(a)

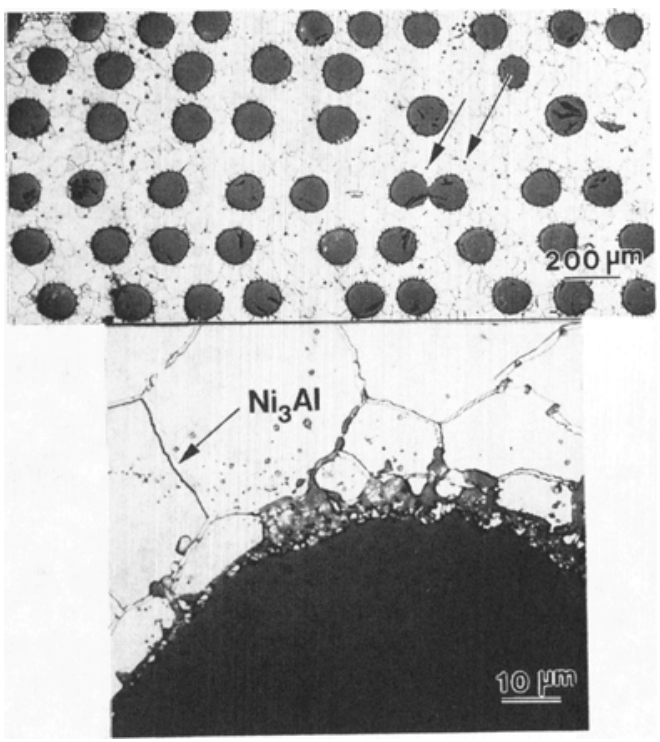

(b)

Fig. 1 - Typical microstructures of the sapphire-fiber-reinforced $\mathrm{NiAl}$ and $\mathrm{NiAl}(\mathrm{Yb})$ composites. Arrows indicate microporosity in the matrix: (a) PM NiAl, (b) PM NiAl(Yb), (c) DS NiAl, (d) DS NiAl(Yb), and (e) HT NiAl(Yb).

\section{Interfacial Reaction}

Figures 2(a) through (c) are back-scattered SEM images of the fiber-matrix interface in the PM, DS, and HT NiAl(Yb) composites, respectively. The sapphire fiber appears dark and the reaction-product layer appears white (or gray). It is apparent that the extent of chemical reaction is much greater in the HT and DS specimens when compared to the PM-NiAl( $\mathrm{Yb})$ specimen. The various phases present in the matrix near the interface are labeled $\mathrm{A}, \mathrm{B}, \mathrm{C}, \mathrm{D}$, and $\mathrm{E}$ in the higher-magnification views shown in the inset for the PM, HT, and DS $\mathrm{NiAl}(\mathrm{Yb})$ composites. The corresponding EDS spectra of these five phases from the PM NiAl(Yb) specimen are presented in Figure 3. Phase $\mathrm{A}$ is present as a continuous layer surrounding the fiber (Figure 2(a)) and contains $\mathrm{Ni}, \mathrm{Al}$, and $\mathrm{O}$ (Figure 3(a)). Phase $\mathrm{B}$, which is also present as a continuous layer beyond the $A$ phase into the matrix (Figure 2(b)), comprises $\mathrm{Yb}, \mathrm{Al}$, and $\mathrm{O}$ (Figure 3(b)). Phase B also appears as "pegs" growing out from the sapphire surface into the intergranular regions of the NiAl matrix. Phase $\mathrm{C}$ is located within phase $\mathrm{B}$ (Figure 2(a)) and contains only $\mathrm{Yb}$ and $\mathrm{O}$ (Figure 3(c)). Phase D, which is the matrix $\beta$ phase (Figures 2(a) and (b)) contains only $\mathrm{Ni}$ and $\mathrm{Al}$ (Figure 3(d)). A comparison of Figures 3(a) and (d) shows that phase $A$ is richer in aluminum than the matrix phase D. In addition, EDS analysis showed that the nickelto-aluminum peak-intensity ratio was $>1$ at the matrix grain boundaries, whereas the NiAl matrix (phase D) had a nickel-to-aluminum ratio of $\simeq 1$. Finally, the $E$ phase, which was dispersed throughout the matrix and seen as bright white spots in Figure 2(a), contained $\mathrm{Yb}$ and $\mathrm{F}$ (Figure 3(e)).

Typical SEM views of fibers extracted from the PM and DS NiAl composites are shown in Figures 4(a) and 4(b) and fibers extracted from the PM, DS, and HT $\mathrm{NiAl}(\mathrm{Yb})$ composites are presented in Figures 4(c) through (e). Also shown is an SEM view of an as-received sapphire fiber (Figure 4(f)). These figures confirm the optical microscopy observations that fibers in the PM, HT, and DS NiAl(Yb) composites have undergone severe chemical attack by the matrix, resulting in extensive 

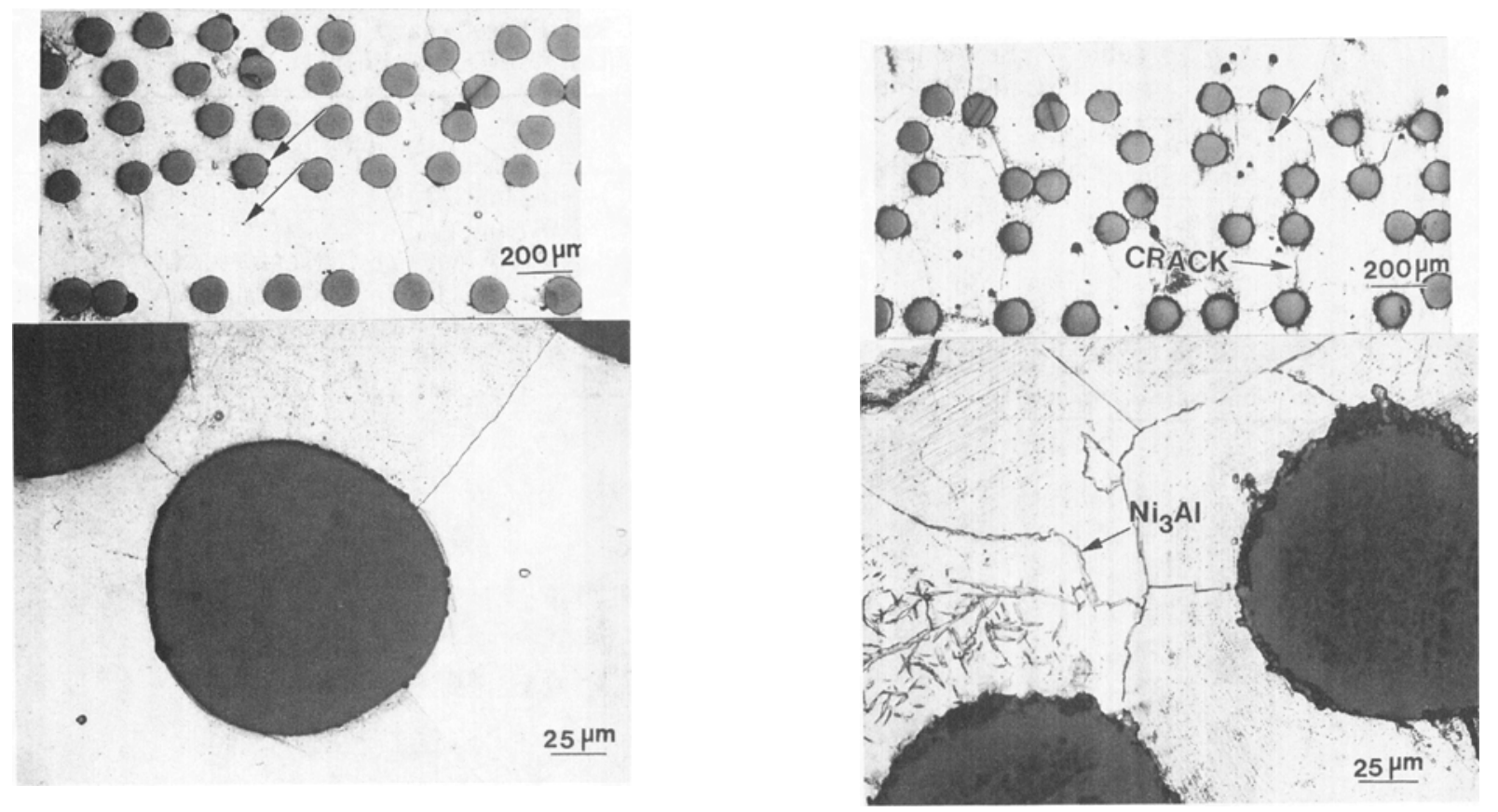

$(c)$

(d)

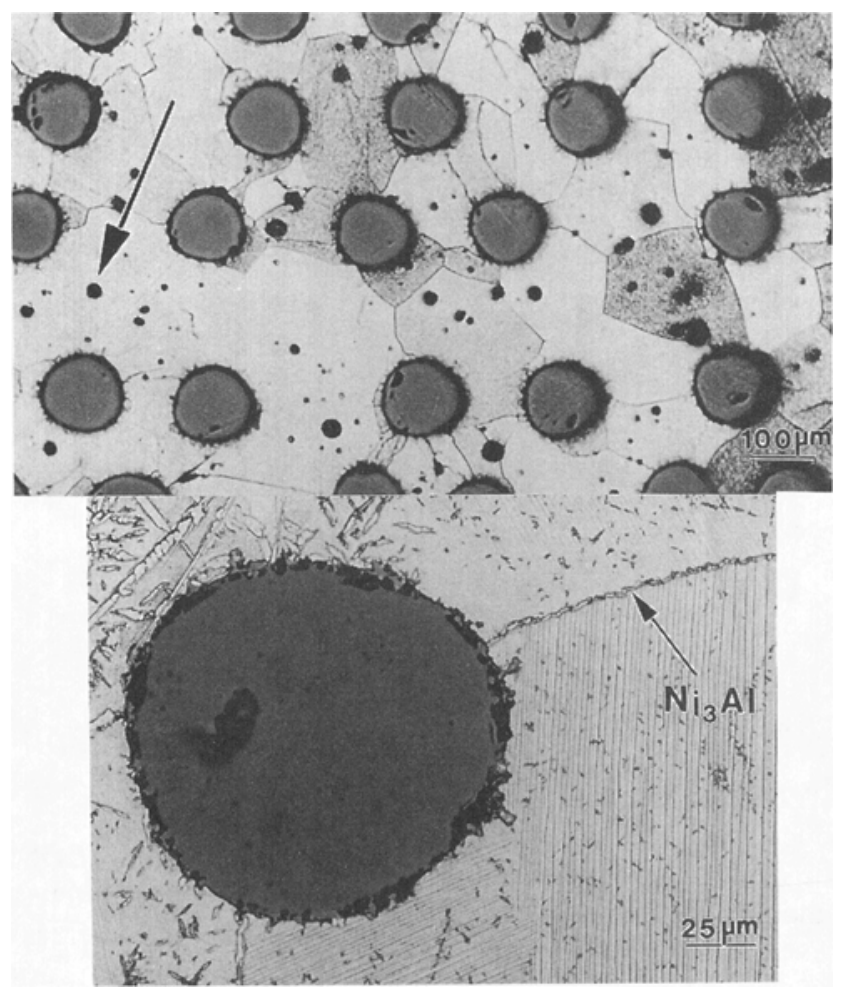

(e)

Fig. 1 Cont. - Typical microstructures of the sapphire-fiber-reinforced $\mathrm{NiAl}$ and $\mathrm{NiAl}(\mathrm{Yb})$ composites. Arrows indicate microporosity in the matrix: (a) PM NiAl, (b) PM NiAl(Yb), (c) DS NiAl, (d) DS NiAlf Yb), and (e) HT NiAl(Yb).

roughening of the fiber. In contrast, the as-received fibers (Figure 4(f)) generally had smooth surfaces, except for occasional asperities, as indicated in Figure 4(f). The surfaces of fibers extracted from the PM NiAl composites (Figure 4(a)) showed evidence of impressions from prior particle boundaries that formed during the powder cloth processing. On the other hand, the fibers extracted from the DS NiAl composites (Figure 4(b)) showed circular features that presumably formed from the gas porosity created during the zone DS process, as shown in 


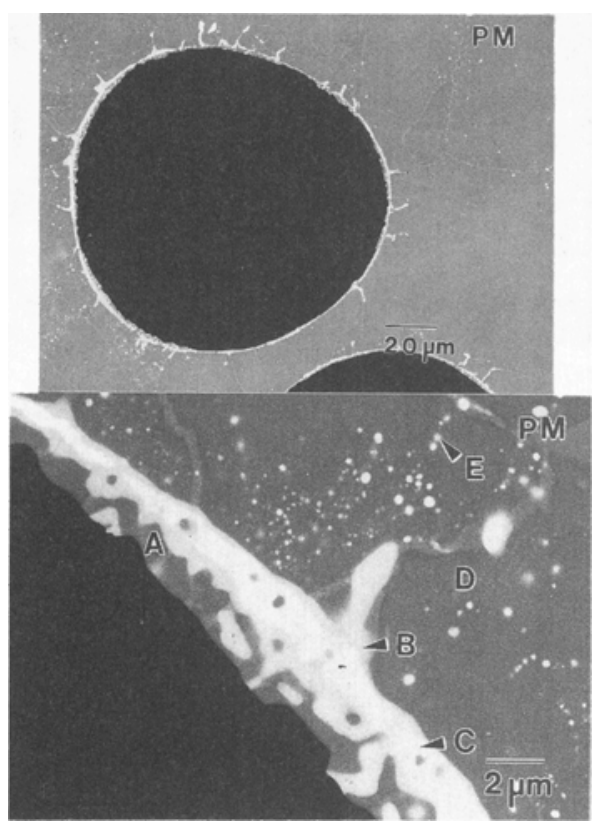

(a)

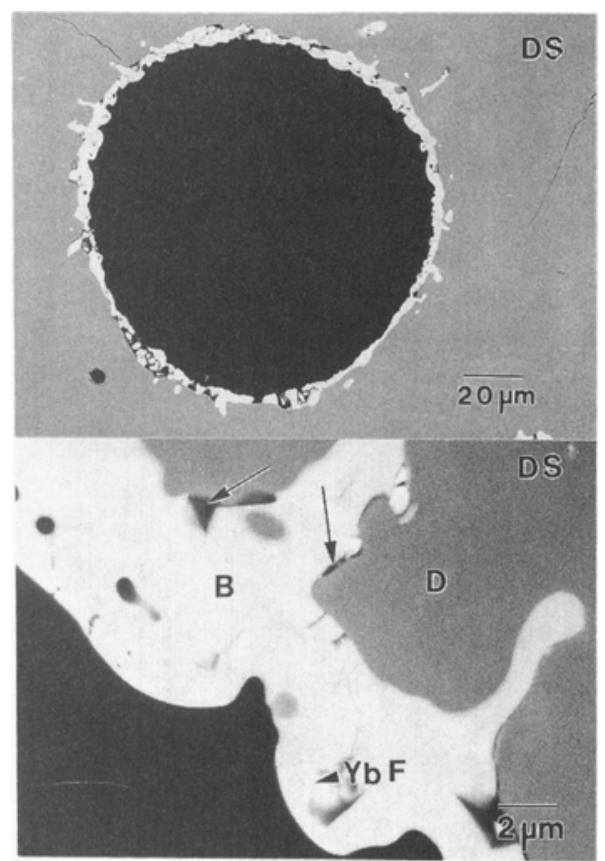

(b)

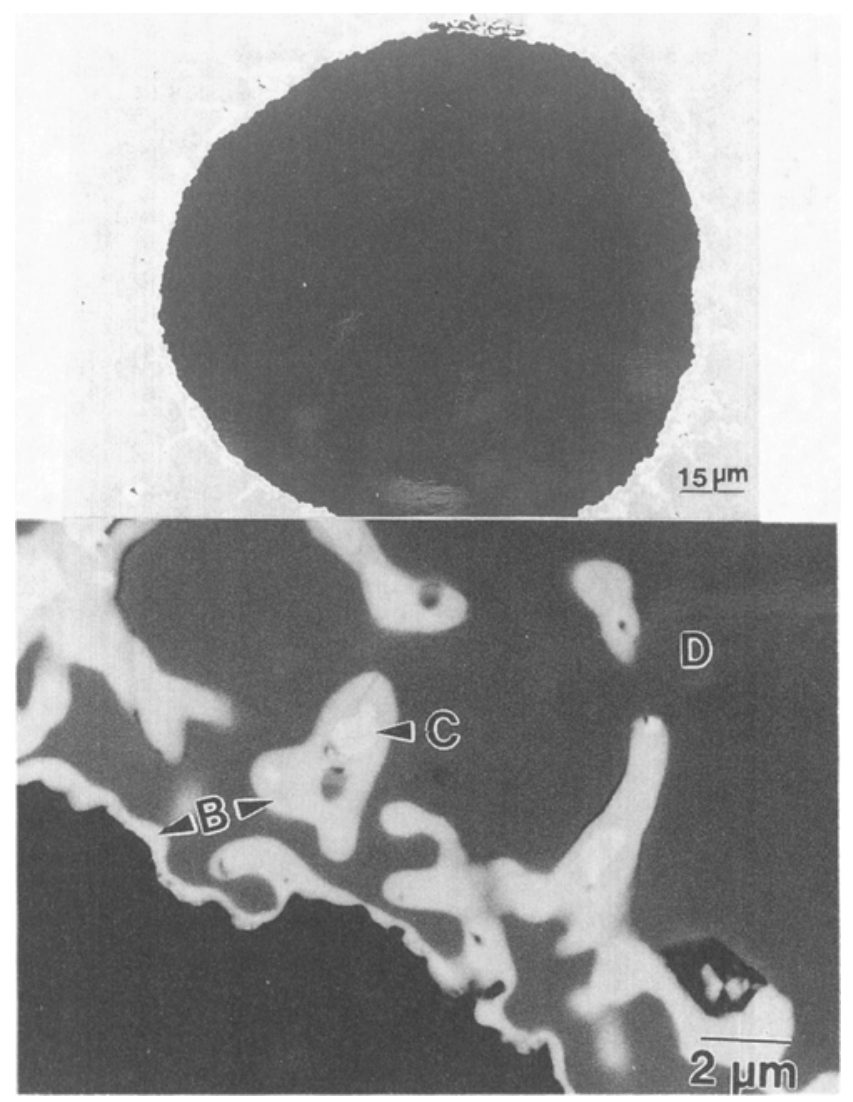

(c)

Fig. 2-Microstructures at the matrix-fiber interface in $(a) \mathrm{PM} \mathrm{NiAl}(\mathrm{Yb})$, (b) DS NiAl(Yb), and (c) $\mathrm{HT} \operatorname{NiAl}(\mathrm{Yb})$. Regions marked A through E denote same phases in PM, HT, and DS composites. 


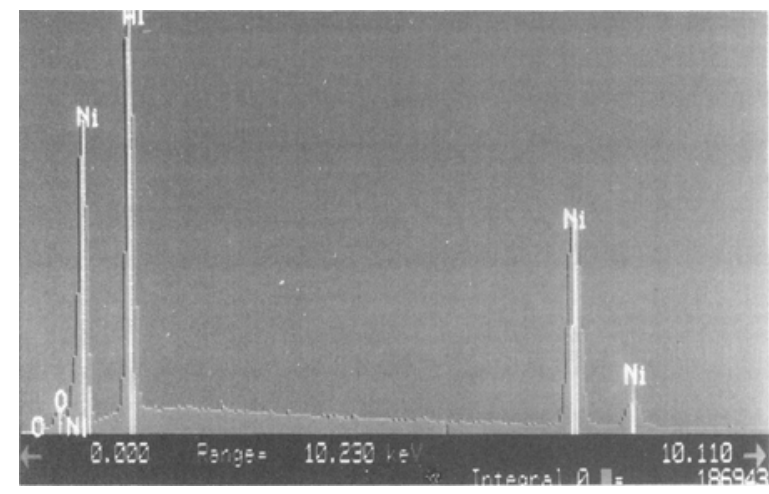

(a)

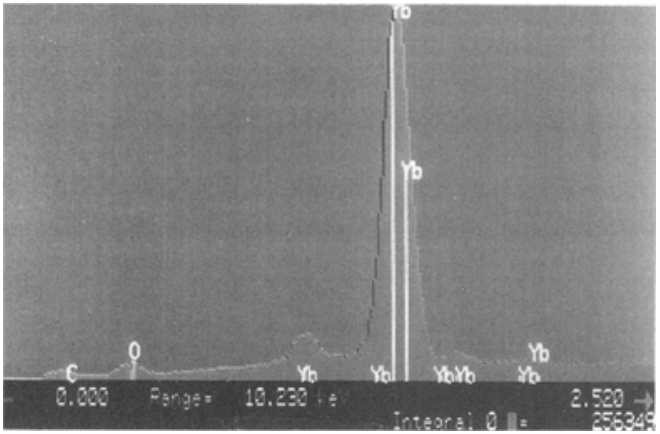

(c)

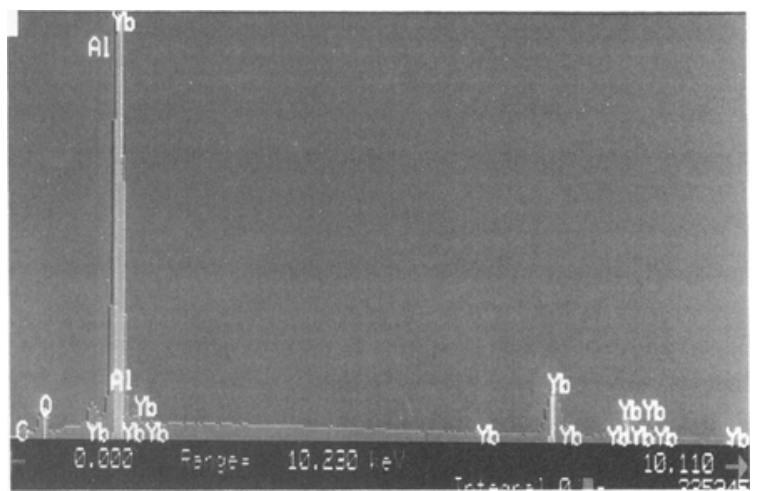

(b)

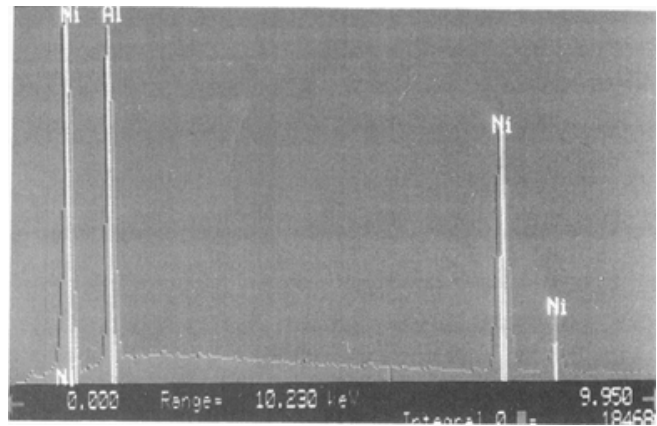

(d)

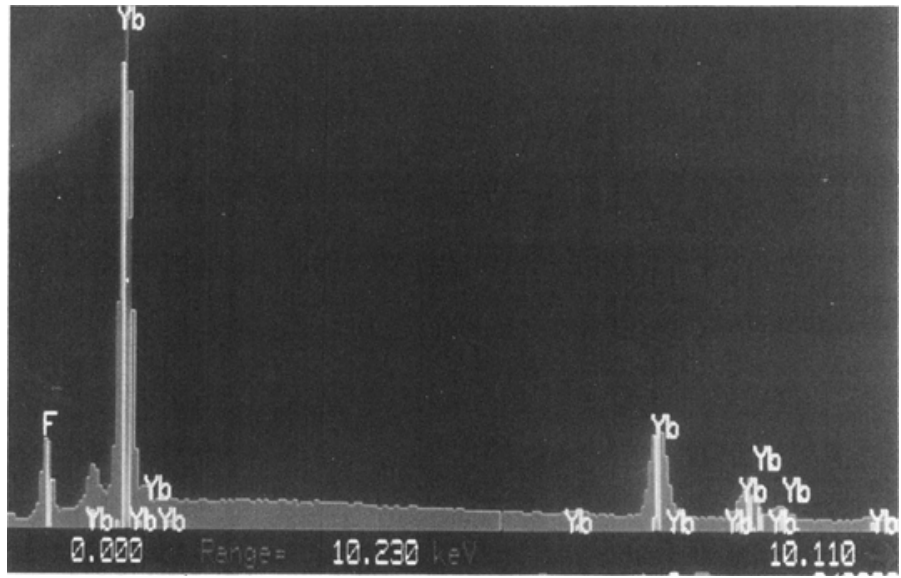

(e)

Fig. 3-EDS analysis of the phases marked A through E in Fig. 2: (a) A is oxygen-rich NiAl; $(b) \mathrm{B}$ is $\mathrm{Yb}_{3} \mathrm{Al}_{5} \mathrm{O}_{12} ;(c) \mathrm{C}$ is $\mathrm{Yb}_{2} \mathrm{O}_{3} ;(d) \mathrm{D}$ is matrix $\mathrm{NiAl}$; and $(e) \mathrm{E}$ is ytterbium fluoride.

Figure 2(a). However, unlike the PM and DS NiAl(Yb) composites, no evidence of chemical attack of fibers was observed in the PM and DS NiAl composites.

\section{Fiber-Pushout Behavior}

Figure 5 shows typical shear stress displacement plots and the accompanying $\mathrm{AE}$ from the fiber-pushout tests on PM and DS NiAl, and PM, DS, and HT NiAl(Yb) composite samples. Pushout stress values were obtained by dividing the pushout load values by the interfacial contact area, $\pi D t$, where $D$ is the fiber diameter and $t$ is the disk thickness. Note that the disk thicknesses $(300$ to $400 \mu \mathrm{m}$ ) are much larger than the total fiber displacement during the pushout process. In general, a three-step stress-displacement response was observed in these composite materials. The three stages of failure process were as follows: an initial linear increase in stress (pseudoelastic region) followed by a nonlinear increase in stress (inelastic region), up to a maximum, whereafter the stress dropped either abruptly, as in the case of NiAl composites (Figures 5(a) and (b)), or gradually, as in the case 


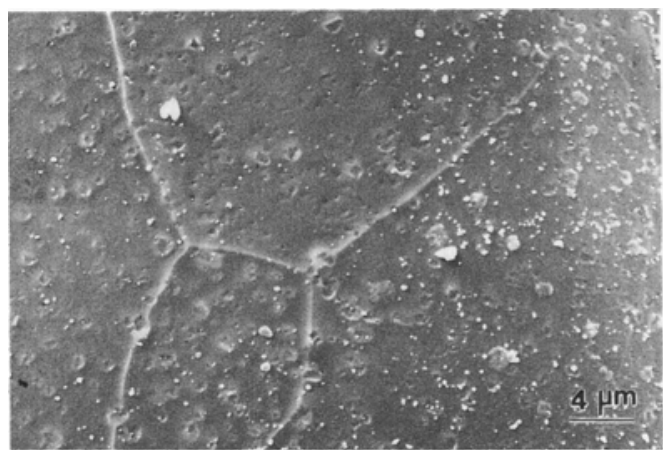

(a)

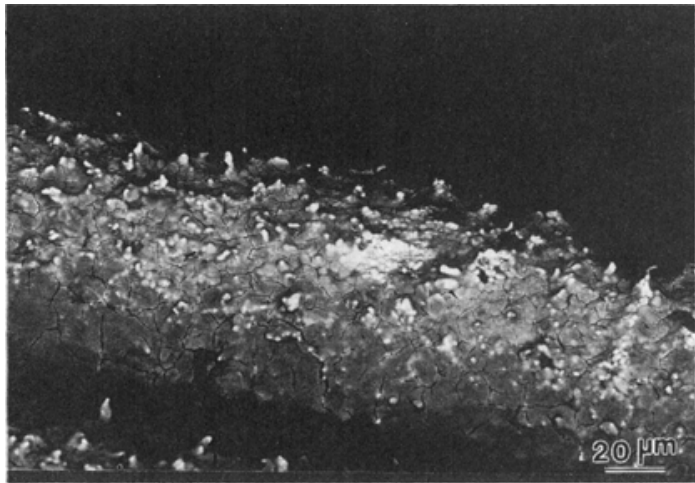

(c)

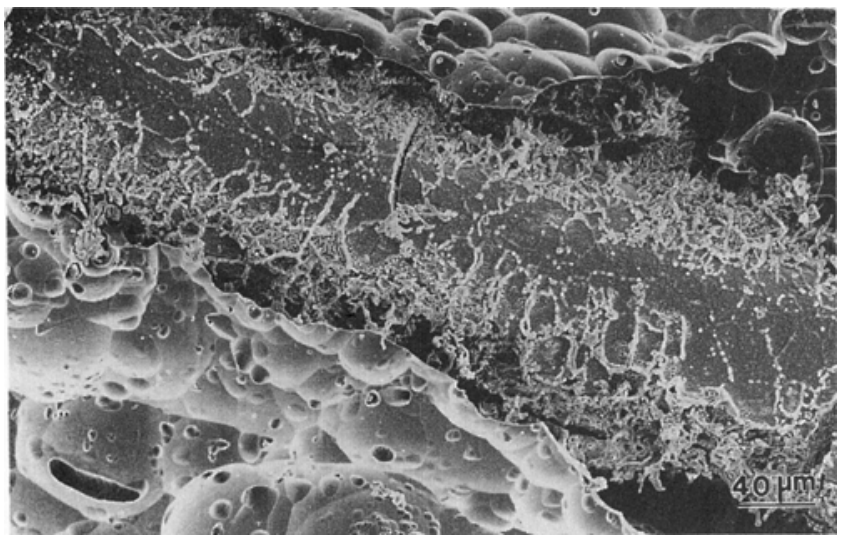

(e)

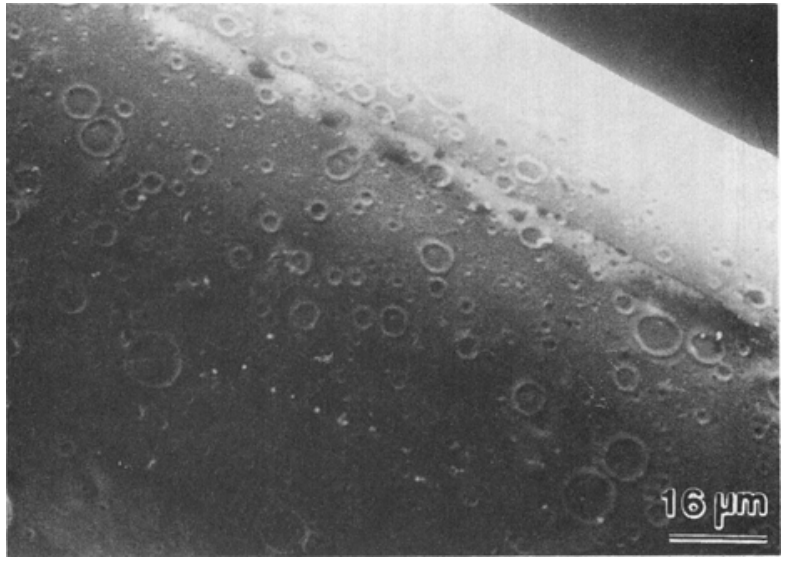

(b)

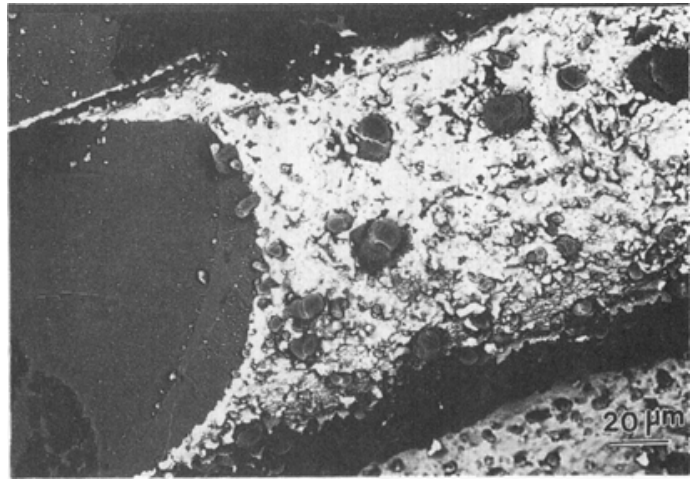

(d)

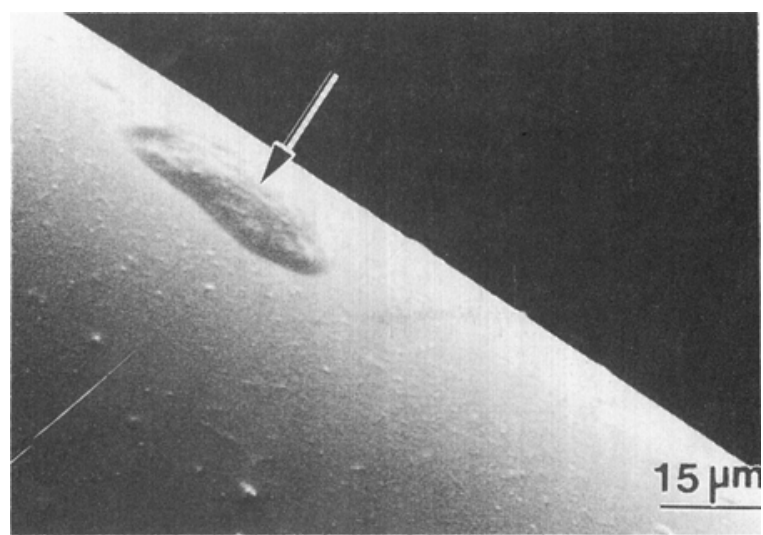

( $f)$

Fig. 4-SEM views of sapphire fibers extracted from different composites: (a) PM-NiAl, (b) DS-NiAl, ${ }^{17}$ (c) PM-NiAl(Yb), (d) DS-NiAl(Yb), and $(e) \mathrm{HT}-\mathrm{NiAl}(\mathrm{Yb})$; and $(f)$ as-received sapphire fiber showing surface asperity.

of $\mathrm{NiAl}(\mathrm{Yb})$ composites (Figures 5(c) through (e)), to some constant value. A gradual stress-drop-type behavior was also observed in a recent study ${ }^{[13]}$ on interfacial shear strength in the sapphire-Ti-48Al-2Cr- $2 \mathrm{Nb}$ system, in which a severe interfacial reaction resulted in a very rough fiber surface.

The pushout behavior will be described in terms of the proportional limit $\left(\tau_{p}\right)$, corresponding to the stress at the transition point between the pseudoelastic and inelastic regions, maximum shear stress $\left(\tau_{m}\right)$, corresponding to the maximum in the stress-displacement curves, and frictional shear stress $\left(\tau_{f}\right)$, obtained at a displacement of $8 \mu \mathrm{m}$ ( 10 seconds) beyond the stress drop. Table II compiles the average $\tau_{p}, \tau_{m}$, and $\tau_{f}$ values and their standard deviations for the composite specimens examined in this study. For some of the fibers in the PM NiAl(Yb) specimens, the maximum load available in the equipment $(40 \mathrm{~N})$ was insufficient to push the fiber out. For these 

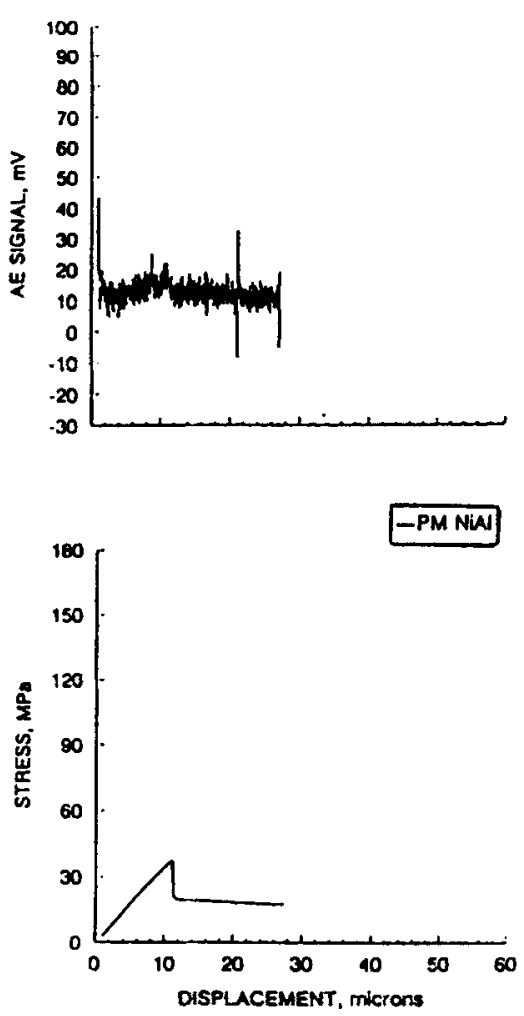

(a)
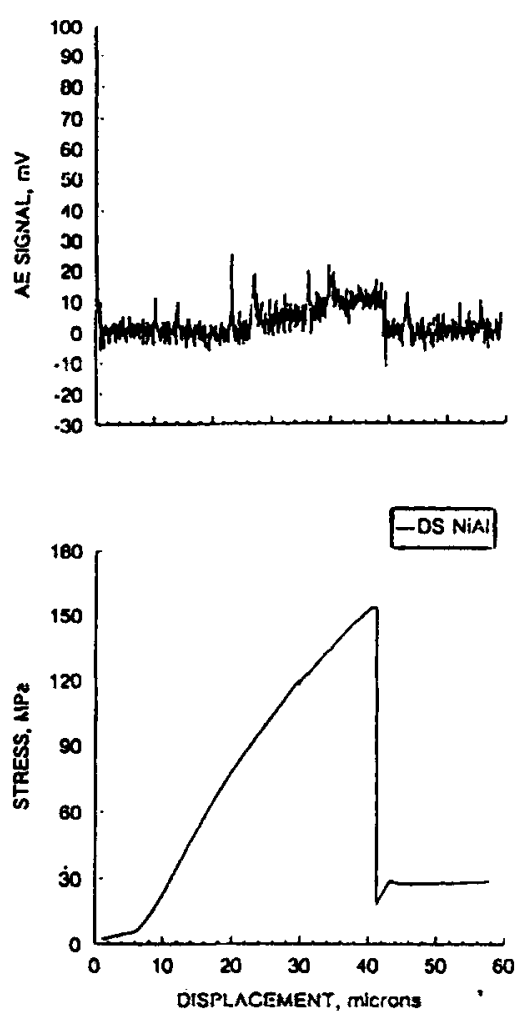

(b)
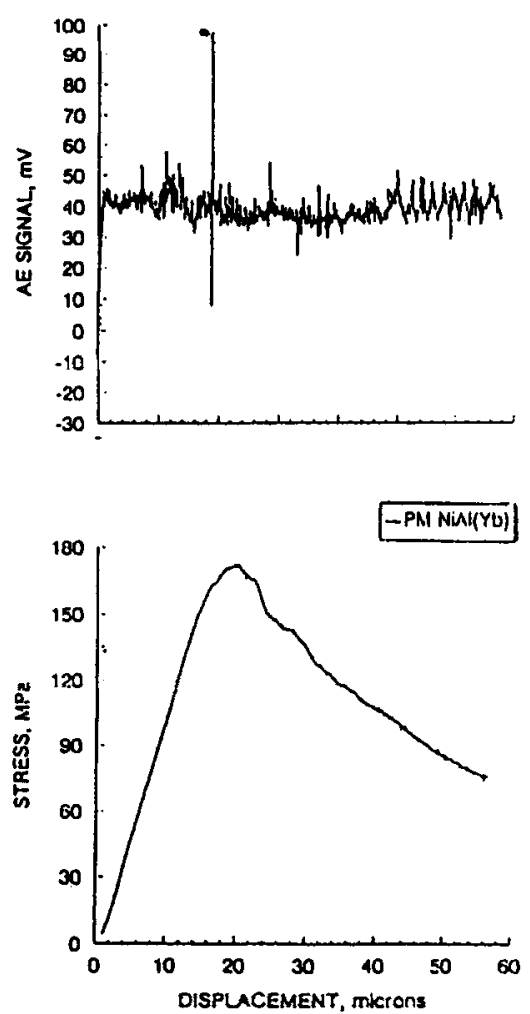

(c)
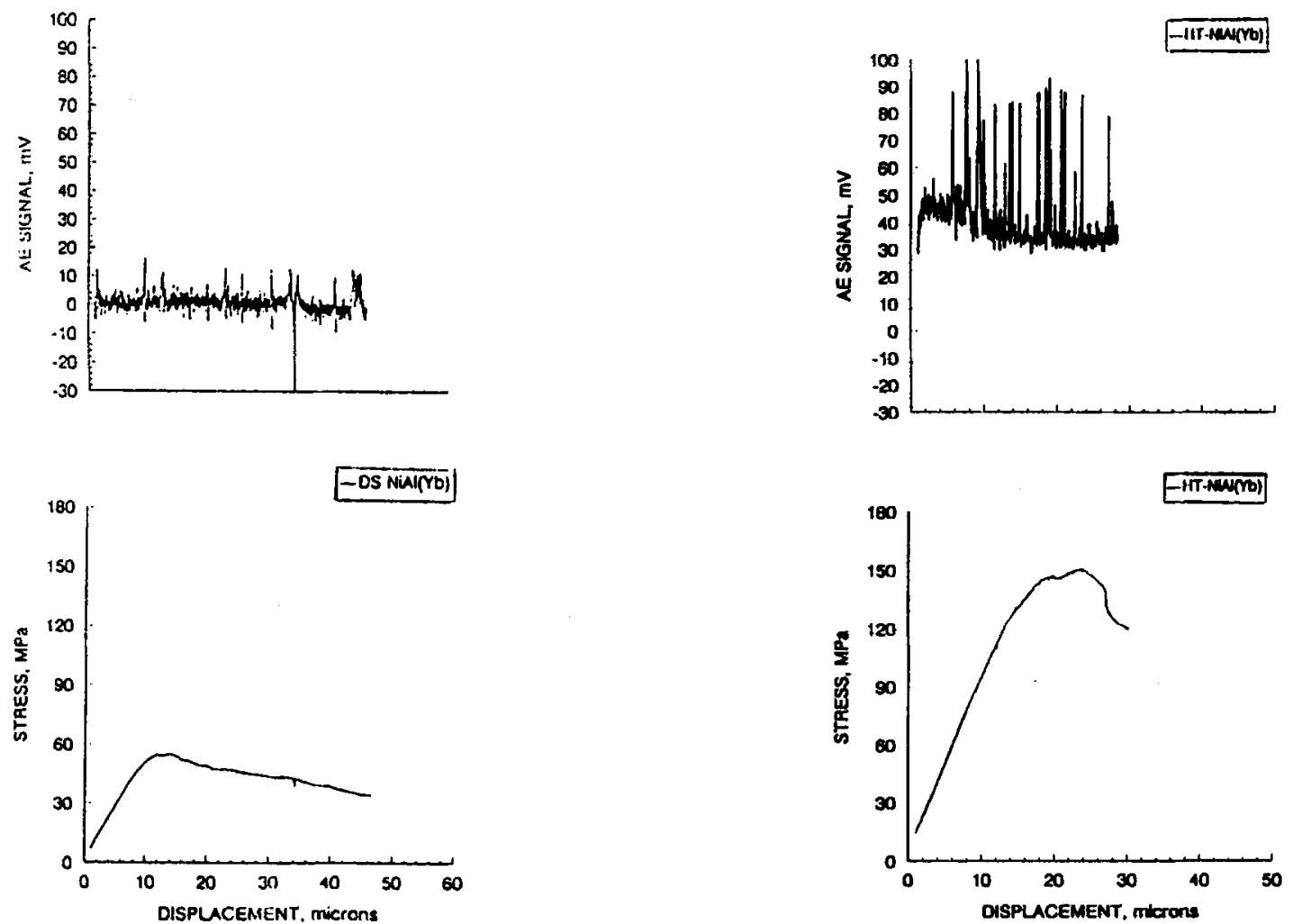

(d)

(e)

Fig. 5- Fiber-pushout response of the sapphire-fiber-reinforced NiAl and NiAl(Yb) composites: (a) PM NiAl, (b) DS NiAl, (c) PM NiAl(Yb), (d) DS NiAl(Yb), and (e) $\mathrm{HT} \mathrm{NiAl(Yb).}$ 
Table II. Fiber-Pushout Characteristics of Sapphire-Fiber-Reinforced NiAl and NiAl(Yb) Composites

\begin{tabular}{|c|c|c|c|c|c|}
\hline Material & $\begin{array}{c}\begin{array}{c}\text { Grain Size } \\
(\mu \mathrm{m})\end{array} \\
\end{array}$ & AE Ratio & $\tau_{p}(\mathrm{MPa})$ & $\tau_{m}(\mathrm{MPa})$ & $\tau_{f}(\mathrm{MPa})$ \\
\hline PM-NiAl & 50 & $10 \pm 4$ & $27 \pm 13$ & $30 \pm 16$ & $20 \pm 13$ \\
\hline DS-NiAl & 1000 & $8 \pm 4$ & $84 \pm 40$ & $138 \pm 62$ & $27 \pm 7$ \\
\hline PM-NiAl(Yb) & 80 & $114 \pm 81$ & $177 \pm 64$ & $>205 \pm 69(24)$ & $126 \pm 16$ \\
\hline HT-NiAl(Yb) & 135 & & $118 \pm 72$ & $164 \pm 64$ & $135 \pm 47$ \\
\hline DS-NiAl(Yb) & $\begin{array}{c}128 \pm 77 \\
230\end{array}$ & $13 \pm 9$ & $47 \pm 28$ & $67 \pm 44$ & $53 \pm 41$ \\
\hline
\end{tabular}

tests, the $\tau_{m}$ and $\tau_{f}$ values could not be obtained. The number of such tests is indicated in Table II in parentheses, and the " $>$ " sign has been used to indicate that the actual mean is probably higher than the values given in the table, which include only the pushed-out fibers. During pushout, the first distinct AE signal was generally detected near $\tau_{p}$. The ratios between the intensity of this AE signal and the background are also compiled in Table II. As indicated in Table II, and typically shown in Figure 5, the AE signal-to-noise ratio in the vicinity of $\tau_{p}$ was significantly larger in the $\mathrm{PM}$ and $\mathrm{HT} \operatorname{NiAl}(\mathrm{Yb})$ specimens compared to the DS specimens. By comparison, both PM and DS NiAl specimens showed significantly weaker $\mathrm{AE}$ peaks.

Because the shear stresses at the onset of inelastic deformation (proportional limit $\tau_{p}$ ) represent the initial debond stress ${ }^{[14]}$ at which tensile cracks are nucleated at the sample backface, Table II shows that higher stresses were needed to nucleate cracks in the DS NiAl specimens $\left(\tau_{p}=84 \pm 40 \mathrm{MPa}\right)$ as compared with the PM $\mathrm{NiAl}$ specimens $\left(\tau_{p}=27 \pm 13 \mathrm{MPa}\right)$. In contrast, the $\mathrm{NiAl}(\mathrm{Yb})$ composites showed an opposite trend; the $\tau_{p}$ values were significantly higher in $\mathrm{PM} \mathrm{NiAl}(\mathrm{Yb})(177 \pm$ $64 \mathrm{MPa})$ and $\mathrm{HT}$ NiAl( $\mathrm{Yb})(118 \pm 72 \mathrm{MPa})$ as compared to the DS NiAl(Yb) $(47 \pm 28 \mathrm{MPa})$. The maximum stress $\tau_{m}$ represents the final debond stress at which complete fiber-matrix debonding occurred. ${ }^{[14]}$ The $\tau_{m}$ values also show a pattern similar to the proportional limit stress $\tau_{p}$ for both materials. Considering only the pushed fibers, the average $\tau_{m}$ values for PM, HT, and DS $\operatorname{NiAl}(\mathrm{Yb})$ specimens were $205 \pm 69,164 \pm 64$, and $67 \pm 44 \mathrm{MPa}$, respectively, compared to the average $\tau_{m}$ values for $\mathrm{PM}$ and $\mathrm{DS} \mathrm{NiAl}$ specimens, which were $30 \pm 16$ and $138 \pm 62 \mathrm{MPa}$, respectively.

The frictional stress $\tau_{f}$ for PM and DS NiAl was nearly the same $20 \pm 13$ and $27 \pm 7 \mathrm{MPa}$, respectively. In contrast, the $\tau_{f}$ values for the $\mathrm{PM} \operatorname{NiAl}(\mathrm{Yb})(126 \pm$ $16 \mathrm{MPa})$ and $\mathrm{HT} \mathrm{NiAl}(\mathrm{Yb})(135 \pm 47 \mathrm{MPa})$ were considerably larger than the $\tau_{f}$ for $\mathrm{DS} \operatorname{NiAl}(\mathrm{Yb})(53 \pm$ $41 \mathrm{MPa}$ ). The frictional stresses for both the PM and DS $\mathrm{NiAl}(\mathrm{Yb})$ specimens were larger than those for the $\mathrm{NiAl}$ specimens.

The proportional shear stress $\tau_{p}$ corresponds to the initiation of the interfacial debond as a result of combined mechanical-loading and thermal-clamping stresses due to coefficient of thermal expansion (CTE) mismatch between the fiber and the matrix. The maximum shear stress $\tau_{m}$ corresponds to the completion of the debonding process. Thus, the stress range from $\tau_{p}$ to $\tau_{m}$ is related to the propagation of debond. The debond progression itself is a complex process and involves the growth of preexisting interfacial microcracks, cracking of matrix grain boundaries that are coincident on the fiber surface, and interfacial and matrix microplasticity. The frictional shear stress $\tau_{f}$ represents the "sliding stress" due to the combined influence of coulumbic friction, asperity (roughness)-controlled friction, and the thermal-clamping stresses at asperity contact points during fiber sliding. The interpretation of test results to obtain bond strength is, therefore, not straightforward. Further complications may be introduced by the fragmentation of fiber into segments of unknown lengths during fiber pushout. Therefore, while the various shear stresses $\left(\tau_{p}, \tau_{m}\right.$, and $\left.\tau_{f}\right)$ obtained from the fiber-pushout test are measures of the strength of the interfacial bond between the fiber and the matrix, the precise relationship of these stresses to the "true" or "intrinsic" bond strength in a multiphase reactive system is difficult to establish.

\section{E. Fracture Behavior}

Unlike the sapphire-NiAl composites in which the fracture behavior during the pushout test was different for the PM and the DS specimens, ${ }^{[7]}$ no differences were observed in the fracture behavior of PM, HT, and DS $\mathrm{NiAl}(\mathrm{Yb})$ specimens. Figure 6 shows typical SEM views of the debonded surfaces for PM and DS NiAl( $\mathrm{Yb})$ specimens after fiber pushout beyond $\tau_{m}$. They both showed backface cracking, similar to the PM and DS NiAl specimens reported earlier. ${ }^{[7]}$ The front faces were generally crack-free, although occasional cracks were observed at the interfacial regions on the front face. Both the fiber and matrix in the fractured regions showed considerable surface heterogeneity, which resulted from the chemical interactions. The debonded matrix surface (Figure 6(c)) showed fine wear tracks parallel to the fiber-sliding direction. Because the asperities generated on the fiber surface resulting from the chemical reaction between the fiber and the matrix in $\mathrm{NiAl}(\mathrm{Yb})$ composites were much coarser than the growth-related surface defects on the asreceived fibers, the plastic grooving of the matrix and the formation of wear tracks were significantly greater in the PM, HT, and DS NiAl(Yb) (Figure 6(c)) compared to the DS NiAl, where fiber-surface roughening resulting from chemical reactions was absent..$^{[7]}$

The fact that no differences in the failure modes could be detected from SEM examination of tested specimens of PM, HT, and DS NiAl( $\mathrm{Yb})$ materials indicates that the failure processes in these materials are far more complex than those in the NiAl material. It is conceivable that matrix grain boundaries coincident on the fiber surface, the different extents of interfacial chemical reactions, somewhat different reaction products, and the 


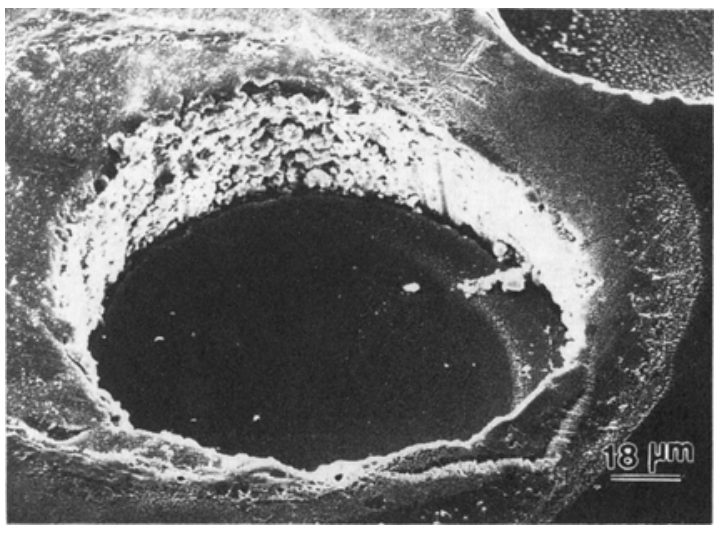

(a)

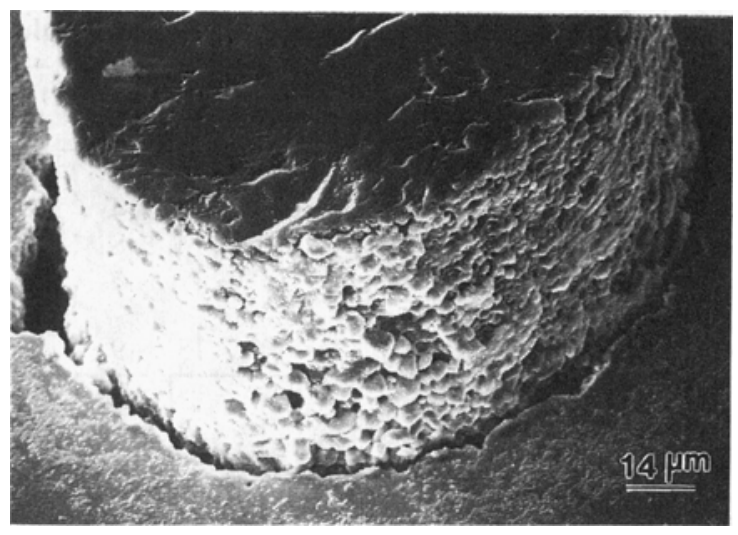

(b)

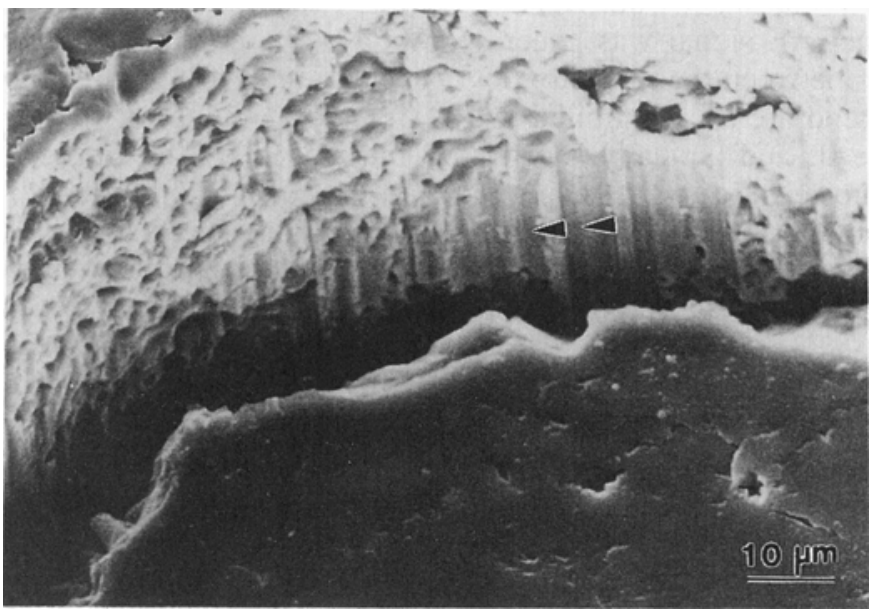

(c)

Fig. 6-Fracture behavior of the sapphire-fiber-reinforced NiAl(Yb) composites: $(a)$ front face and $(b)$ back face. $(c)$ Wear tracks resulting from microplastic grooving from fiber asperities during fiber sliding.

variations in the thickness and morphology of the reaction layers in the PM, HT, and the DS NiAl(Yb) materials would all contribute to the debonding and failure processes. The combined influence of these factors on the failure modes is presumably too complex to show up as a systematic behavior.

\section{DISCUSSION}

An examination of the $\mathrm{Ni}-\mathrm{Al}$ phase diagram (Figure 7(a)) shows that the NiAl composites (Ni-50 at. pct $\mathrm{Al})$ had a single $\beta$-phase matrix. The $\mathrm{NiAl}(\mathrm{Yb})$ composites (Ni-37 at. pct $\mathrm{Al})$ are, however, expected to consist of $\mathrm{NiAl}(\beta)$ and $\mathrm{Ni}_{3} \mathrm{Al}\left(\gamma^{\prime}\right)$ phases (Figure $7(\mathrm{a})$ ). As presented in Table I, $\gamma^{\prime}$ was detected only in the HT and DS $\mathrm{NiAl}(\mathrm{Yb})$ by $\mathrm{X}$-ray diffraction and not in PM $\mathrm{NiAl}(\mathrm{Yb})$, although optical microscopy indicated $\gamma^{\prime}$ in the PM NiAl(Yb), which was confirmed by the EDS analysis of the light phase at the grain boundaries (Figure 2(a)). Because this phase showed only nickel and aluminum, and its nickel-to-aluminum ratio was higher than that in the NiAl matrix, it can be assumed that this phase is $\mathrm{Ni}_{3} \mathrm{Al}$. Also, $\mathrm{X}$-ray analysis did not show the presence of martensite in the $\mathrm{DS} \mathrm{NiAl}(\mathrm{Yb})$, although its presence was revealed by metallography (Figure $1(d)$ ).

\section{A. Interfacial Microstructure}

The following sequence of reactions can be hypothesized for the formation of the interfacial microstructures (Figures 2(a) through (c)) in the PM, DS, and HT $\mathrm{NiAl}(\mathrm{Yb})$ composites. Ytterbium is a chemically active rare-earth element, as well as a strong oxide former. The standard free energies of formation of $\mathrm{Yb}_{2} \mathrm{O}_{3}$ and $\mathrm{Al}_{2} \mathrm{O}_{3}$ are $-1727.50 \mathrm{~kJ} \cdot \mathrm{mol}^{-1}$ and $-1583.10 \mathrm{~kJ} \cdot \mathrm{mol}^{-1}$, ${ }^{191} \mathrm{re}-$ spectively. In the $\mathrm{PM} \mathrm{NiAl(Yb)}$ composite, the reaction between ytterbium in the matrix and $\mathrm{Al}_{2} \mathrm{O}_{3}$ fibers leads to the dissolution of the fiber and to aluminum and oxygen enrichment of the surrounding NiAl (" $A$ " in Figure 2(a)). The diffusion of oxygen into the matrix (away from the sapphire fibers) and of ytterbium toward the fibers leads to the formation of $a \mathrm{Yb}_{2} \mathrm{O}_{3}$ layer around the sapphire fiber (" $\mathrm{C}$ " in Figure 2(a)). Because of the oxygen enrichment of the original powder surface, the $\mathrm{Yb}_{2} \mathrm{O}_{3}$ phase is also formed on the grain boundaries (prior powder boundaries) throughout the matrix. The $\mathrm{Yb}_{2} \mathrm{O}_{3}$, located on the matrix grain boundaries which were in 


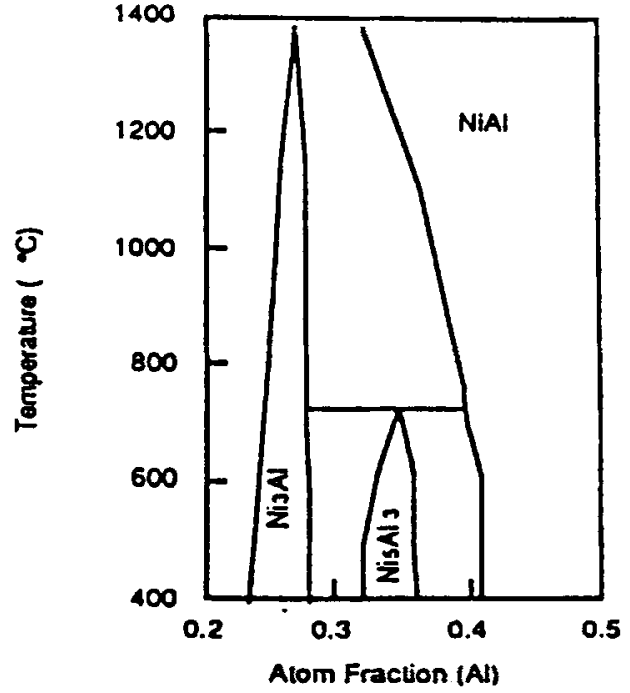

(a)

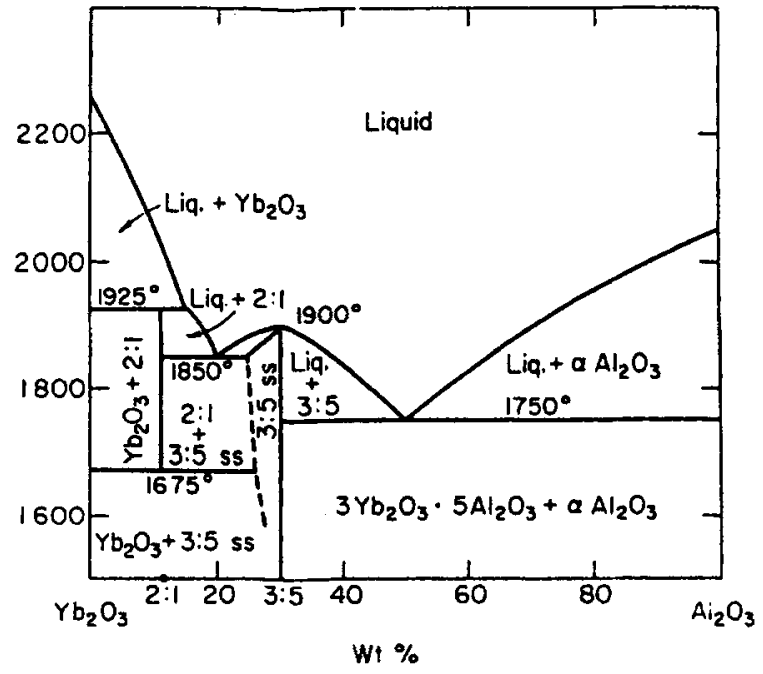

(b)

Fig. $7-(a) \mathrm{Ni}-\mathrm{Al}$ phase diagram ${ }^{[16 i}$ and $(b) \mathrm{Yb}_{2} \mathrm{O}_{3}-\mathrm{Al}_{2} \mathrm{O}_{3}$ phase diagram.118]

contact with the sapphire fibers, initiates the formation of the pegs described previously. The $\mathrm{Yb}_{2} \mathrm{O}_{3}$ is subsequently consumed because of a reaction with $\mathrm{Al}_{2} \mathrm{O}_{3}$, leading to the formation of the $\mathrm{Yb}_{3} \mathrm{Al}_{5} \mathrm{O}_{12}$, which is essentially a spinel oxide $\left(\mathrm{Yb}_{2} \mathrm{O}_{3}\right.$ to $\mathrm{Al}_{2} \mathrm{O}_{3}$ ratio of $\left.3: 5\right)$ (Figure 7(b)). Elevated-temperature exposure of PM $\mathrm{NiAl}(\mathrm{Yb})$ composite, in the $\mathrm{HT} \mathrm{NiAl}(\mathrm{Yb})$ specimens, for example, has been observed to result in an almost complete absence of $\mathrm{Yb}_{2} \mathrm{O}_{3}$ in the vicinity of the fiber and its conversion into $\mathrm{Yb}_{3} \mathrm{Al}_{5} \mathrm{O}_{12}$ (Figure 2(c)). The presence of fluorine in the TEFLON* ${ }^{*}$ binder, used during

${ }^{*}$ TEFLON is a trademark of E.I. DuPont de Nemours and Co. Inc., Wilmington, DE.

the $\mathrm{PC}$ processing of composites, accounts for the ytterbium- and fluorine-rich dispersoids observed in the $\mathrm{NiAl}$ matrix.

The thermal profile imposed on the composite specimens during zone DS leads to an initial solid-state heating of the specimen before the formation of the melt zone. Apparently, the $\mathrm{NiAl}$ layer surrounding the sapphire fibers and also the $\mathrm{Yb}_{2} \mathrm{O}_{3}$ layer in the $\mathrm{PM}$ composite are completely consumed during this high-temperature exposure, leading to the formation of a thick $\mathrm{Yb}_{3} \mathrm{Al}_{5} \mathrm{O}_{12}$ layer that surrounds the fibers and the $\mathrm{Yb}_{3} \mathrm{Al}_{5} \mathrm{O}_{12}$ pegs protruding from the fiber surface. Subsequently, during the DS, the $\mathrm{NiAl}$ alloy melts around these $\mathrm{Yb}_{3} \mathrm{Al}_{5} \mathrm{O}_{12}$ layers and goes through the process of solidification and cooling to the room temperature. Solidification shrinkages result, especially in the crevices in the vicinity of these pegs (marked by arrows in Figure 2(b)) because of an insufficient metallostatic head. The pegs also constrict the shrinkage of the matrix during cooling to room temperature in both HT and DS specimens, and the stresses thus generated cause severe cracking of the $\mathrm{NiAl}$ matrix, as observed in the DS and $\mathrm{HT} \mathrm{NiAl}(\mathrm{Yb})$ composites (Figures 1(d) and (e)). The reaction sequence previously proposed for the formation of various reaction products is, however, conjectural but not implausible. Detailed research of the reaction mechanisms and reaction paths was not attempted in the present study.
In summary, the following microstructural features are of interest in the NiAl composites. (1) There was minimal degradation of the sapphire fiber surface, and (2) the number of grain boundaries in contact with the fiber in PM composites was much greater than in the HT and DS composites. In the PM NiAl(Yb) composite, the fiber was surrounded mostly by the oxygen-rich $\mathrm{NiAl}$ layer, except for the $\mathrm{Yb}_{3} \mathrm{Al}_{5} \mathrm{O}_{12}$ phase pegs, which grew from the fiber surface into the intergranular regions of the matrix. In the HT and DS NiAl(Yb) composite, the fiber was not in contact with $\mathrm{NiAl}$; instead, it was surrounded by a layer of $\mathrm{Yb}_{3} \mathrm{Al}_{5} \mathrm{O}_{12}$ phase, about 5- $\mu \mathrm{m}$ thick in the DS $\mathrm{NiAl}(\mathrm{Yb})$ and $<0.5-\mu \mathrm{m}$ thick in the HT $\operatorname{NiAl}(\mathrm{Yb})$ composite.

\section{B. Fiber Pushout Behavior}

Recent finite element modeling studies ${ }^{[17]}$ of fiberpushout behavior in a "thin-slice" test configuration suggest that thermal stresses (due to CTE mismatch) and mechanical stresses (due to loading) can generate radial stresses large enough to nucleate fine cracks at the sample back face that propagate along the interface and lead to interface failure. Interrupted pushout test and fractography of sapphire-NiAl composites ${ }^{[7]}$ failed to detect any front- or back-face cracks on the test specimens when the test was interrupted at $\tau_{p}$. However, a high AE signalto-noise ratio was generally observed in the vicinity of $\tau_{p}$ (Table II), suggesting that some micromechanical events, possibly too weak to leave gross microstructural manifestation, do occur at the fiber-matrix interface, at $\tau_{p}$. On the other hand, when the test was interrupted at $\tau>\tau_{m}$, both the front (Figure 8(a)) and back faces (Figure 8(b)) of PM-NiAl specimens showed ${ }^{[7]}$ extensive interfacial cracking along grain boundaries that were coincident on the fiber. The fibers in the DS NiAl showed both grain boundary cracking and circumferential decohesion along part of the fiber-matrix interface on the front (Figure 8(c)) and back (Figure 8(d)) faces of the samples. For the fibers completely embedded within 


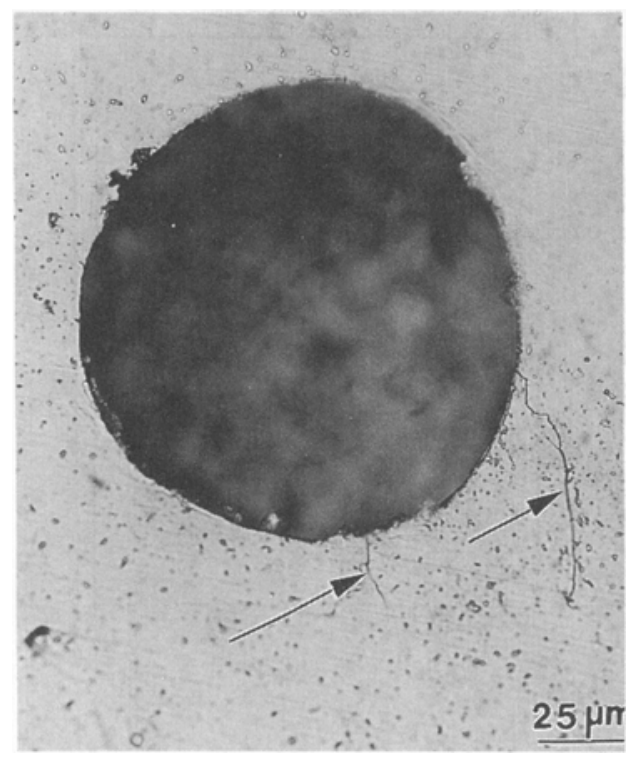

(a)

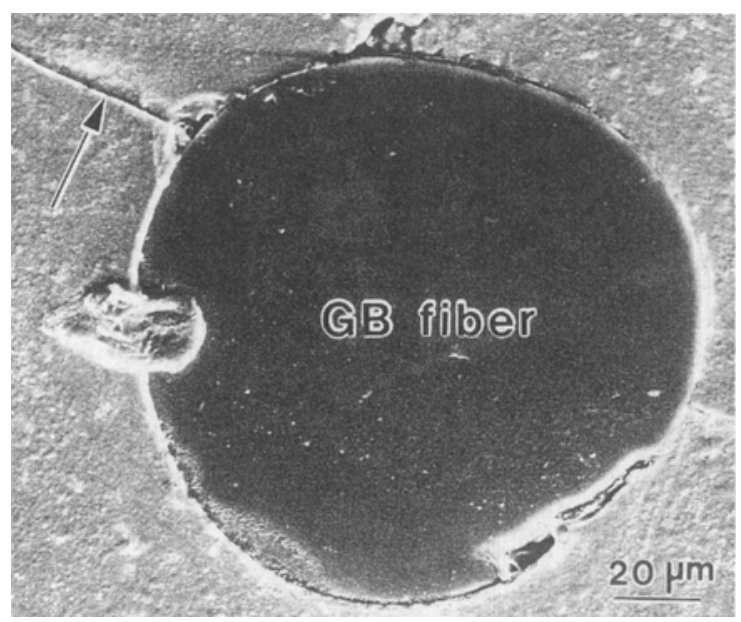

(c)

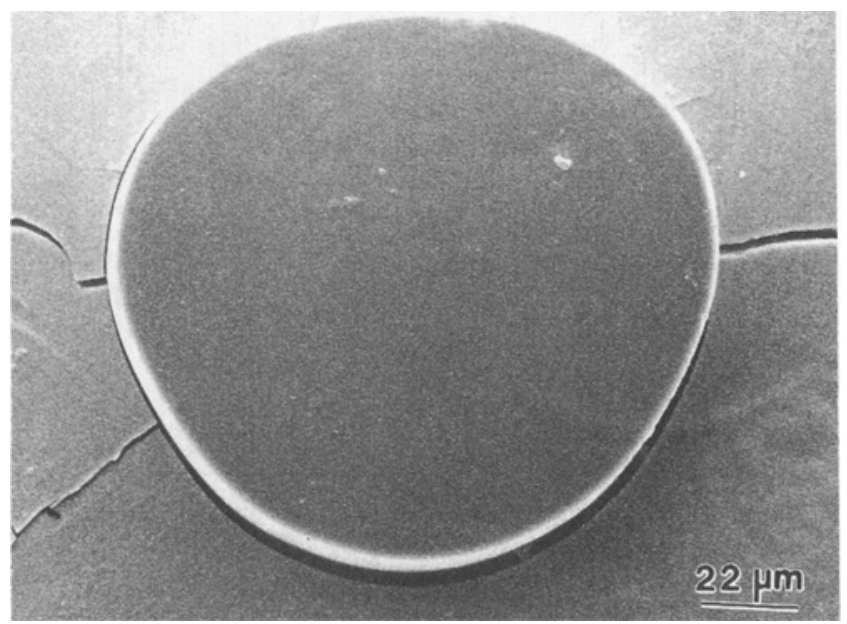

(b)

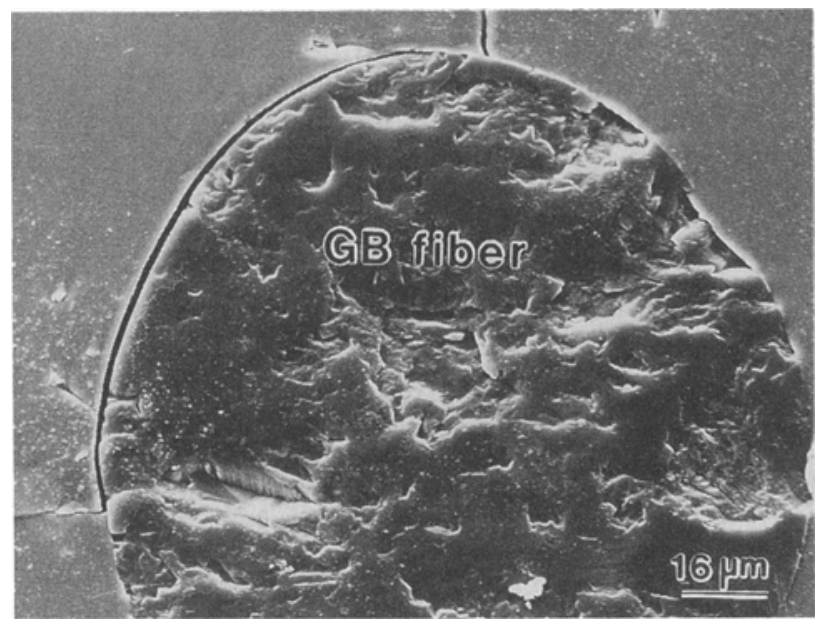

(d)

Fig. 8 - Fracture behavior of the sapphire-fiber-reinforced NiAl composites: $(a)$ PM front face; $(b)$ PM back face; $(c)$ DS front face for fiber at a grain boundary; $(d)$ DS back face for fiber at a grain boundary; $(e)$ DS front face for fiber within a grain; $(f)$ DS back face for fiber within a grain; and $(g)$ plastic grooving of the NiAl matrix.

the NiAl grains in the DS specimens, the front faces were free of interfacial damage (Figure $8(\mathrm{e})$ ), but the back faces (Figure $8(f)$ ) showed partial fiber-matrix debonding together with fine radial cracks; these fibers displayed the highest interfacial shear strength. Thus, radial grain boundaries in contact with the fiber surface are not only the preferred site for nucleation of these cracks but also provide an easy path for crack growth. The sapphire fibers in the PM NiAl, because of a small matrix grain size, had the maximum number of such grain boundaries, resulting in easy nucleation of such cracks and the lowest $\tau_{p}$ values. The fibers in the DS materials, with a fewer number of such grain boundaries, showed larger $\tau_{p}$ values. ${ }^{171}$ Also, in both PM and DS sapphire-NiAl composites, localized microplastic grooving of the matrix by fiber asperities was observed (Figure $8(\mathrm{~g})$ ), in a manner similar to the present sapphire- $\mathrm{NiAl}(\mathrm{Yb})$ system (Figure 6(c)).

These results show that the deformation processes that occur during fiber pushout are influenced by the nature of the fiber-matrix interface and the matrix microstructure, both of which are influenced by processing. In the absence of an interfacial chemical reaction (as in $\mathrm{PM}$ and DS NiAl), the progressive elimination of matrix grain boundaries by DS enhanced the fiber-matrix interfacial shear strength. ${ }^{\text {[7] }}$ However, when an extensive chemical reaction between the fiber and the matrix was induced by alloying $\mathrm{NiAl}$ with $\mathrm{Yb}$, the influence of interfacial reactions dominated the matrix microstructure in the vicinity of the fiber in determining the interfacial shear strength.

As described in Section III, only the DS and the HT 


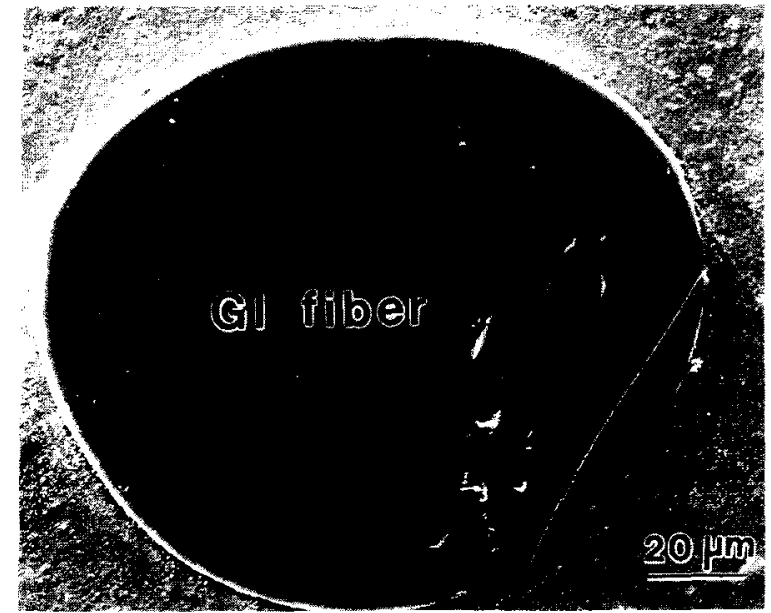

(e)

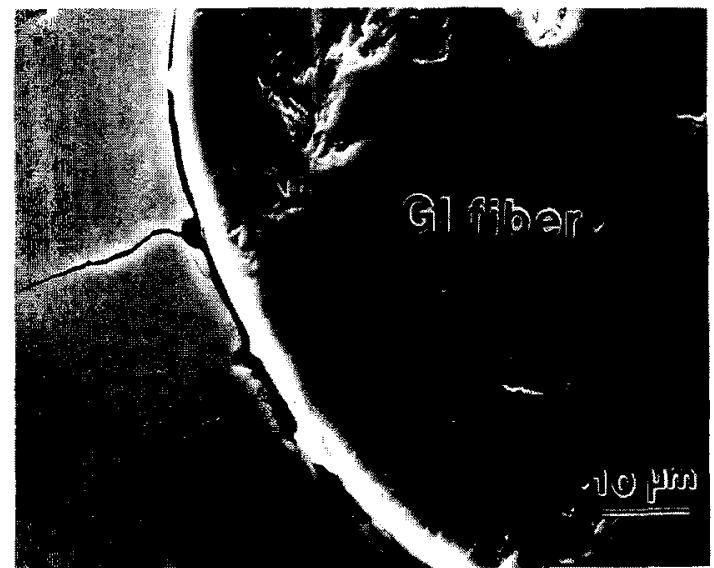

(f)

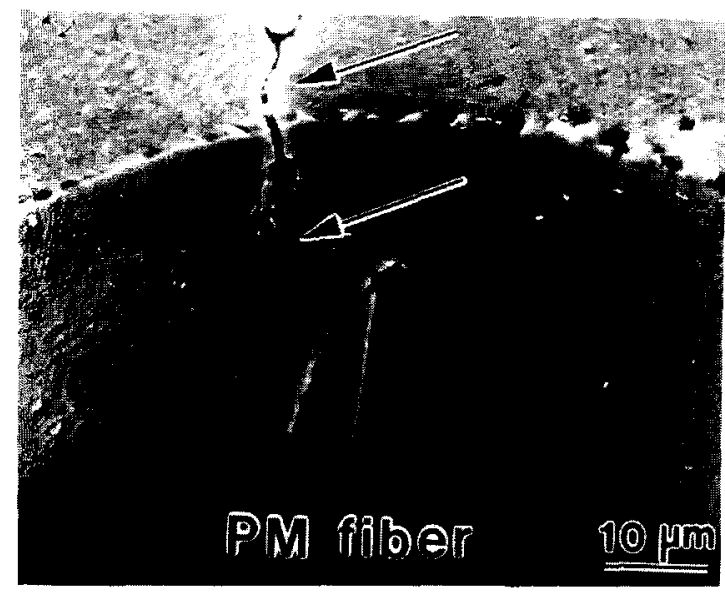

(g)

Fig. 8 Cont. - Fracture behavior of the sapphire-fiber-reinforced NiAl composites: $(a)$ PM front face; $(b)$ PM back face; $(c)$ DS front face for fiber at a grain boundary; $(d)$ DS back face for fiber at a grain boundary; $(e)$ DS front face for fiber within a grain; $(f)$ DS back face for fiber within a grain; and $(g)$ plastic grooving of the NiAl matrix.

$\mathrm{NiAl}(\mathrm{Yb})$ test specimens showed matrix cracking; the PM material did not show cracking, although it had numerous grain boundaries coincident on the fiber-matrix interface in a manner similar to the PM NiAl specimens. However, unlike the grain boundaries in the PM NiAl specimens, the grain boundaries in the $\mathrm{NiAl}(\mathrm{Yb})$ matrix showed presence of the hard and brittle intermetallic $\mathrm{Ni}_{3} \mathrm{Al}$ (Figures $1(\mathrm{~b}),(\mathrm{d})$, and (e)). The role of grain boundaries in the failure processes associated with fiber debonding during fiber pushout is, therefore, expected to be different in the $\mathrm{NiAl}(\mathrm{Yb})$ and $\mathrm{NiAl}$ materials. In particular, the grain boundaries coincident on the fiber surface in the $\mathrm{NiAl}(\mathrm{Yb})$ are not expected to serve as sites favorable for crack nucleation and growth, as they did in the NiAl material, because of the presence of the $\mathrm{Ni}_{3} \mathrm{Al}$ phase at grain boundaries. Thus, despite the presence of numerous grain boundaries in both PM NiAl and PM NiAl( $\mathrm{Yb})$ materials, the latter material, by comparison, showed significantly greater $\tau_{p}$ and $\tau_{m}$ values, as well as AE ratios (Table II), because the strengthening effects of chemical bonding were not offset by the weakening effects of grain boundaries as a result of the presence of
$\mathrm{Ni}_{3} \mathrm{Al}$ phase at grain boundaries. On the other hand, the cracks formed during processing of HT and DS NiAl(Yb) materials did not have the $\mathrm{Ni}_{3} \mathrm{Al}$ phase present. Therefore, such cracks are expected to overcome the advantage of enhanced chemical bonding in the $\mathrm{NiAl}(\mathrm{Yb})$ material by assisting the debonding processes during fiber pushout. This is revealed most dramatically when the $\tau_{p}$ values and the $\mathrm{AE}$ ratios of $\mathrm{PM} \mathrm{NiAl(Yb)} \mathrm{(no} \mathrm{cracking)}$ materials and DS NiAl(Yb) (extensive cracking) materials are compared (Table II).

In contrast to the $\mathrm{NiAl}$, where DS resulted in improved $\tau_{p}$ because of the elimination of transverse grain boundaries, the DS NiAl(Yb) specimens showed a reduction in $\tau_{p}$ and $\tau_{m}$, as compared with the $\mathrm{PM} \operatorname{NiAl}(\mathrm{Yb})$. Once a chemical bond is established between the fiber and the matrix in the PM NiAl(Yb) composite, the increase in the extent of chemical attack of the fiber by the matrix during the HT and zone DS is not expected to provide any additional interfacial strengthening. Consequently, no change in the $\tau_{p}$ and $\tau_{m}$ values would be expected between the PM, HT, and DS NiAl(Yb) composites. The fact that the DS composites had, in fact, 
lower interfacial shear strengths compared to the PM specimens can be attributed to the extensive interfacial cracking between $\mathrm{Yb}_{3} \mathrm{Al}_{5} \mathrm{O}_{12}$ and $\mathrm{NiAl}$ matrix and also to the presence of shrinkage cavities located there in the DS samples (marked by arrows in Figure 2(b)).

As the onset of inelastic instability at $\tau_{p}$ indicates initial debonding, ${ }^{[14]}$ a higher $\tau_{p}$ value is expected to be associated with a stronger AE signal. This is indeed the case, as noted from Table II. Of all the composite specimens examined in this study, the PM and HT NiAl(Yb) specimens (with the highest $\tau_{p}$ values) showed largest values of the signal-to-noise ratios. The $\mathrm{DS} \mathrm{NiAl}(\mathrm{Yb})$ composite showed a lower AE signal-to-noise ratio because of the relatively smaller energy released at the onset of debonding. On the other hand, the relatively smooth fiber-matrix interfaces of the PM and DS NiAl composites, as compared with the $\mathrm{NiAl}(\mathrm{Yb})$ composites, yielded the lowest AE signal-to-noise ratios, as seen from Table II.

It is well known that a certain amount of chemical interaction between the fiber and the matrix is essential for improving the strength of the interfacial bond; however, the extent of this interaction must be carefully controlled to achieve an optimum bond. An excessive chemical attack of the fiber by the matrix degrades the fiber strength because of surface "notches," which cause premature fiber failure without yielding any load-bearing advantage of the fiber. In the PM NiAl(Yb) composites, the existence of a chemical bond as opposed to a purely "frictional" bond ${ }^{[3]}$ suggests that the interfacial shear strength should be high. This is indeed the case and is reflected in the high values of $\tau_{p}$ and $\tau_{m}$ for this composite. However, as a result of the extreme reactivity of the sapphire- $\mathrm{NiAl}(\mathrm{Yb})$ system, the advantage of improved chemical bonding is realized at the expense of the fiber strength and surface quality. As the focus in the present work was the strength of the interface rather than that of the bulk composite, the highly reactive sapphire-NiAl( $\mathrm{Yb}$ ) model system was chosen. As a cautionary note, we reiterate that no strengthening of the bulk composite is to be expected by reinforcing the $\mathrm{NiAl}(\mathrm{Yb})$ matrix by sapphire fibers because of the extreme degradation of the latter during composite fabrication.

Once the fibers are completely debonded at $\tau_{m}$, the frictional sliding of the fiber in the matrix is affected mainly by the fiber-surface roughness. Therefore, the friction stress in the PM and DS NiAl composites would be expected to be about the same, as is observed (Table II), because of the relatively smooth fiber-matrix interface in the NiAl composites. On the other hand, the rougher fiber surface and the presence of pegs in the $\mathrm{NiAl}(\mathrm{Yb})$ composites are responsible for much larger friction stresses observed in the $\mathrm{NiAl}(\mathrm{Yb})$ composites.

\section{CONCLUSIONS}

The following conclusions can be drawn from this study on the deformation and fracture behavior during pushout testing of sapphire fibers in sapphire-fiber-reinforced Powder Cloth processed, heat treated, and directionally solidified $\mathrm{NiAl}(\mathrm{Yb})$ composites.
1. The addition of ytterbium causes extensive reaction between the matrix and sapphire fibers. In the PM $\mathrm{NiAl}(\mathrm{Yb})$ composite, the fiber is surrounded mostly by the oxygen-rich $\mathrm{NiAl}$ layer, except for the $\mathrm{Yb}_{3} \mathrm{Al}_{5} \mathrm{O}_{12}$ phase pegs, which grow from the fiber surface into the intergranular regions of the matrix. In the HT and the DS NiAl(Yb) composites, the fiber is not in contact with NiAl but, instead, is surrounded by a layer of $\mathrm{Yb}_{3} \mathrm{Al}_{5} \mathrm{O}_{12}$ phase.

2. The stress $v s$ displacement response during fiber pushout consists of three regimes: (a) an initial region of constant slope up to a stress $\tau_{p}$, followed by (b) a region of decreasing slope up to a maximum stress $\tau_{m}$, and (c) a subsequent gradual stress drop and onset of frictional sliding at a stress $\tau_{f}$. The occurrence of a strong $\mathrm{AE}$ signal near $\tau_{p}$ indicates that this stress corresponds to the onset of fiber-matrix debond. Complete debonding occurred at $\tau_{m}$ and large-scale, postdebond fiber sliding occurred at a progressively decreasing friction stress $\tau_{f}$.

3. The PM and HT NiAl(Yb) specimens showed higher $\tau_{p}$ and $\tau_{m}$ values because of the formation of a chemical bond between the fiber and the matrix, as opposed to the sapphire-NiAl composite in which the bond is purely frictional in nature. These stress values are, however, lower in the DS NiAl( $\mathrm{Yb}$ ) composite because of the microcracks and shrinkage cavities at the $\mathrm{Yb}_{3} \mathrm{Al}_{5} \mathrm{O}_{12}$-matrix interface. The frictional stress for postdebond fiber sliding in the sapphire- $\mathrm{NiAl}(\mathrm{Yb})$ composites was significantly higher than that in the sapphire- $\mathrm{NiAl}$ composites.

\section{ACKNOWLEDGMENTS}

This research was supported by a grant from the NASALewis Research Center (Grant No. NCC-3-287) and also in part from the State of Ohio Research Challenge Program. The authors would like to thank W.J. Brindley for providing the $\mathrm{NiAl}(\mathrm{Yb})$ powder, J.I. Eldridge for helpful discussion on the fiber-pushout test, and T.K. Glasgow for continuous encouragement.

\section{REFERENCES}

1. R. Darolia: J. Met., 1991, vol. 43 (3), 44

2. R.D. Noebe, A. Misra, and R. Gibala: J. Iron Steel Inst. Jpn., 1991, vol. 31, pp. 1172-85.

3. R.D. Noebe, R.R. Bowman, and J.I. Eldridge: in Materials Research Society Symposia Proceedings, D.L. Anton, R. McMeeking, D. Miracle, and P. Martin, eds., Materials Research Society, Pittsburgh, PA, 1990, vol. 194, pp. 323-33.

4. J.W. Pickens, R.D. Noebe, G.K. Watson, P.K. Brindley, and S.L. Draper: NASA-TM 102060, NASA Lewis Research Center, Cleveland, $\mathrm{OH}, 1989$

5. R.R. Bowman: in Materials Research Society Symposia Proceedings, D.B. Miracle, D.L. Anton, and J.A. Graves, eds., Materials Research Society, Pittsburgh, PA, 1992, vol. 273, p. 145.

6. S.N. Tewari, R. Asthana, and R.D. Noebe: Metall. Trans. A, 1993, vol. 24A, pp. 2119-25.

7. R. Asthana, S.N. Tewari, and R.R. Bowman: NASA Lewis Research Center, Cleveland, OH, unpublished research, 1993.

8. A.K. Misra: NASA-CR 4171, NASA Lewis Research Center, Cleveland, OH, 1984.

9. CRC Handbook of Chemistry and Physics, 65th ed, CRC Press, Boca Raton, FL.

10. K.N. Strafford: High Temp. Technol., 1983, vol. 1, p. 307. 
11. J.I. Eldridge: NASA-TM 105341, NASA Lewis Research Center, Cleveland, $\mathrm{OH}, 1991$.

12. P.S. Khadkikar, I.E. Locci, K. Vedula, and G.M. Michal: Metall. Trans. A, 1993, vol. 24A, pp. 83-94.

13. J.M. Galbraith, M.H. Kallas, D.A. Koss, and J.R. Hellman: NASA HITEMP Review 1992, 28-1, NASA CP-10104, 1992.

14. L.J. Ghosn, P. Kantzos, J.I. Eldridge, and R. Wilson: NASA HITEMP Review 1992, 27-5, NASA CP-10104, 1992.

15. C.A. Moose, D.A. Koss, and J.R. Hellman: in Materials Research Society Symposia Proceedings, D.L. Anton, R. McMeeking,
D. Miracle, and P. Martin, eds., Materials Research Society, Pittsburgh, PA, 1990, vol. 194, pp. 293-99.

16. P.S. Khadkikar, K. Vedula, and B.S. Shabel: in Materials Research Society Symposia Proceedings, Materials Research Society, Pittsburgh, PA, 1987, vol. 81, p. 157.

17. D.A. Koss, R.R. Petrich, M.N. Kallas, and J.R. Hellman: Compos. Sci. Technol., 1994, vol. 51, pp. 27-33.

18. E.M. Levin and H.F. McMurdie: Phase Diagrams for Ceramists, 1975 Supplement, American Ceramic Society, Westerville, $\mathrm{OH}$, 1975 , p. 132. 